\title{
Reproducing Single-Carrier Digital Modulation Schemes for VLC by Controlling the First Switching Harmonic of the DC-DC Power Converter Output Voltage Ripple
}

\author{
Juan Rodríguez ${ }^{1}$, Student Member, IEEE, Pablo F. Miaja ${ }^{2}$, Member, IEEE, Diego G. Lamar ${ }^{1}$, Member, \\ IEEE, and Javier Sebastián ${ }^{1}$, Senior Member, IEEE. \\ Departamento de Ingeniería Eléctrica, Electrónica, de Computadores y Sistemas, Universidad de Oviedo, Gijón \\ 33204, Spain \\ (e-mail: rodriguezmjuan@uniovi.es)
}

Power System Division, European Space Agency, Noordwijk 2201 AZ, The Netherlands

(e-mail: pablo.fernandez@esa.int)

\begin{abstract}
A DC-DC power converter based on a twophase synchronous buck converter that reproduces singlecarrier digital modulation schemes by controlling the first switching harmonic of the output voltage ripple is presented in this work. The DC-DC power converter carries out both the lighting and the transmission functionalities of Visible Light Communication (VLC) transmitters. Control of both the amplitude and the phase of sinusoidal currents injected towards High-Brightness LEDs (HB-LEDs) enables the use of efficient modulation schemes such as Quadrature Amplitude Modulation (QAM), Carrier-less Amplitude and Phase modulation (CAP), Amplitude-Shift Keying (ASK) and Phase-Shift Keying (PSK). These modulation schemes achieve higher spectral efficiency (i.e., more data can be transmitted using the same bandwidth) than previously proposed modulation schemes performed by VLC transmitters based on the use of DC-DC power converters. To the author's knowledge, the ratio between the bit rate achieved and the switching frequency of the DC-DC power converter presented in this paper is the highest that can be found in literature.
\end{abstract}

Index Terms - Two-phase buck converter, Quadrature Amplitude Modulation (QAM), Carrier-less Amplitude and Phase modulation (CAP), Amplitude-Shift Keying (ASK), Phase-Shift Keying (PSK), high frequency, output voltage ripple, Visible Light Communication (VLC), High-Brightness LED (HB-LED).

\section{INTRODUCTION}

$\mathrm{N}$ OWADAYS, the use of wireless communication systems is essential to fulfill the massive connectivity demand. For instance, the mobile data traffic has grown exponentially during last decade and it is expected that it keeps growing by 2021 [1].
Another example is that the Internet of Thing (IoT) is becoming a mainstream tend. The idea consists in using wireless communication systems to connect different kinds of items such as clothes, cars, city lighting and home appliances [2]-[3]. Although all these ideas seem to be interesting, there is an important problem that need to be solved to enable them: the Radio Frequency (RF) spectrum is limited and alternative solutions are needed in order to avoid the congestion predicted for upcoming years.

Visible Light Communication (VLC) could be one of these solutions [4]-[7]. It is a wireless communication system that uses the wide and unlicensed visible light spectrum (430-750 $\mathrm{THz}$ ) instead of the RF spectrum ( $3 \mathrm{kHz}-300 \mathrm{GHz})$ to transmit information. The strength of this approach arises when the communication is combined with the lighting functionality of High-Brightness LED (HB-LED) bulbs. Thus, the exiting lighting infrastructure can be partially modified to incorporate the communication capability.

Since its introduction in 2004 [8], VLC has been mainly studied by research groups from the communication field, focusing their efforts on increasing the bit rate. However, there are some bottlenecks that barely have been improved since then. One of them is particularly interesting for power electronics researchers: the low power efficiency achieved by the HB-LED driver of the VLC transmitters that reproduce advanced modulation schemes. This paper aims to alleviate this problem by proposing a technique that enables the reproduction of certain advanced modulation schemes with a DC-DC power converter.

The paper is organized as follows. The fundamentals of VLC are described in Section II. The modulation schemes that can be reproduced by using the method presented in this paper are listed and explained in Section III. The requirements and two 
initial approaches for reproducing these modulation schemes with DC-DC power converters are detailed in Section IV. The definitive method is presented in Section V. The experimental results are given in Section VI and finally, the conclusions are gathered in Section VII.

\section{FUNDAMENTALS OF VLC}

This section introduces the VLC application, highlighting the major achievements and the limitations. It will help readers to understand the objective of this research and its contribution. More detailed VLC reviews can be found in [5]-[13].

\section{A. Operating Principle of $V L C$}

In VLC, the information transmission is achieved by modulating the light intensity, technique that is referred as Intensity Modulation/Direct Detection (IM/DD) [14]. This modulation must be fast enough to be unappreciable to the human eye (i.e., above $100 \mathrm{~Hz}$ approximately [15]-[16]). The Direct Current (DC) bias of the HB-LEDs sets the lighting level, whereas the Alternating Current (AC) component is responsible for the information transmission. Fig. 1 shows the schematic of the ideal VLC transmitter. At the receiver (Fig. 2), a photodiode converts the optical input power into a current signal that is transformed into a voltage signal by a transimpedance amplifier (TIA). The rest of the receiver stages depends on the modulation scheme but, in general, a band-pass filter and a demodulator are included.

\section{B. Light Emitting Diodes for VLC}

VLC was initially proposed for taking advantage of the HBLEDs of lighting applications. The preferred approach for designing such HB-LEDs consists in using a blue Gallium Nitride (GaN) HB-LED that excites a yellow inorganic phosphor. The combination of the blue light with the yellow coating generates white light. However, this phosphor is optimized for color conversion, but not for achieving a very rapid response to the light intensity changes. In fact, it limits the HB-LED bandwidth to a few $\mathrm{MHz}(3-5 \mathrm{MHz})$ [17]-[18]. A more expensive approach for obtaining white light is to combine the red, green and blue light of RGB HB-LEDs. In this way, a bandwidth around $10-20 \mathrm{MHz}$ per color could be achieved [19]. In any case, since the available bandwidth is quite limited, achieving high data rates is a challenging task.

\section{Techniques for Enhancing the Available Bandwidth}

During last years, several techniques have been proposed to increase the available bandwidth:

Blue light filtering: As previously explained, the yellow phosphor of GaN HB-LEDs limits the bandwidth to a few MHz. Using a blue filter at the receiver to reject the yellow component increases the bandwidth to the range of 10-20 MHz [17].

Post-equalization: A post-equalizer is a band-pass filter placed in the receiver that boosts a certain frequency band. In VLC, it is frequently used for compensating the attenuation introduced by the HB-LEDs in the tens of $\mathrm{MHz}$ range (i.e., just above the available bandwidth). In combination with the blue light filtering technique, it is a solution that enables a bandwidth

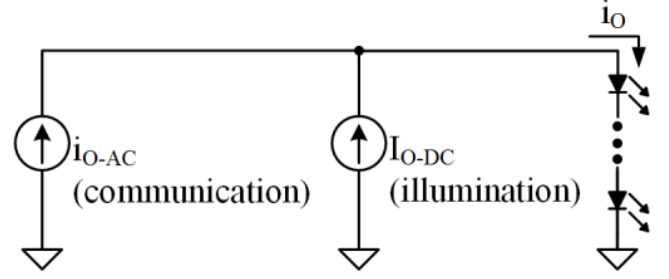

Fig. 1. Ideal VLC transmitter scheme.

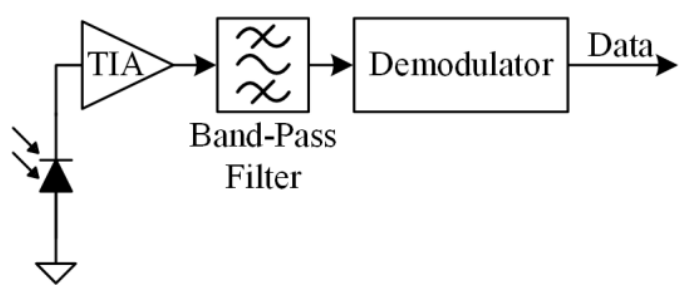

Fig. 2. General VLC receiver scheme.

above $50 \mathrm{MHz}$ [18]-[19].

Color exploitation: The transmitter bandwidth also can be improved by taking advantage of the light color. However, this feature is only possible when using RGB HB-LEDs. Basically, there are two possible approaches. The first one is referred as Wavelength Division Multiplexing (WDM) and considers each HB-LED as an independent transmitter, thus achieving three channels with a bandwidth of around $20 \mathrm{MHz}$ for each one [20][25]. The second approach is known as Color-Shift Keying (CSK) and is a modulation scheme that transmits data by performing small variations of the light color [26]-[28].

Alternative Lighting Devices: Replacing HB-LEDs by other lighting devices is one of the most controversial methods for increasing the available bandwidth. It implies giving up the power efficiency, cost, maturity and reliability of widely adopted HB-LEDs. The researches that study this strategy are mainly focused on a technology referred as $\mu$-LEDs, which consists in reducing the HB-LED size to increase the bandwidth [29]-[31]. Obviously, the amount of optical power that each device can deliver also decreases and, therefore, $\mu$-LEDs arrays must be employed.

Multiple-Input Multiple-Output (MIMO): In general, several HB-LED bulbs can be found in an indoor environment and each one can be considered as an independent transmitter. Moreover, a bulb is frequently made up of several HB-LEDs so each bulb can be split into smaller VLC transmitters. However, since all the communication channels are using the same frequency band, the difficulty is differentiating the data streams of each channel at the receiver. The MIMO technique exploits this idea considering $n$ transmitters and $n$ receivers [32]-[35]. The key point is that each transmitter has a different orientation, thus transmitting most of the optical power to only one of the receivers. Therefore, the distinguishing criterion is based on the multipath propagation. Through the use of this technique, the link capacity is multiplied by $n$.

\section{Modulation Schemes and Proposed HB-LED Drivers}

One of the cornerstones of VLC is the practical implementation of the transmitter according to the modulation 
scheme that is going to be reproduced. The straightforward method for transmitting information consists in generating light pulses by turning-on and off the HB-LEDs at high speed (i.e., pulse-based modulation schemes). Fig. 3 shows the two most extended approaches for performing that method: using a MOSFET in series [36]-[37] or in parallel [38]-[40] with the HB-LED string. In these methods, the data rate is determined by the pulse waveform frequency, which is strongly limited by the HB-LED bandwidth.

There are two options for increasing the bit rate. The first way is to apply one or more of the techniques for increasing the bandwidth that are described in section II.C [17]-[20]. The second way is to replace pulse-based modulation schemes by advanced modulation schemes that provide high efficiency from the communication perspective. This high communication efficiency, which is evaluated in terms of spectral efficiency [41], implies that more data can be transmitted using the same bandwidth. For instance, a sinusoidal waveforms that changes both the amplitude and the phase to transmit the information is more efficient than the mentioned pulse-based modulation schemes. Obviously, the techniques for increasing bandwidth can be used in a VLC transmitter that reproduces efficient modulation schemes. The key point is that considering the use of the same bandwidth enhance techniques for both pulse-based and efficient modulation schemes, the last ones achieve higher bit rates. The combination of efficient modulation schemes and different techniques for enhancing the available bandwidth can be found in [21]-[25] and [42]-[45].

In order to reproduce the waveforms of efficient modulation schemes, two HB-LED drivers have been widely used. The first one [Fig. 4(a)] consists in a MOSFET operating in linear mode and, therefore, acting as a current source controlled by the gate voltage [46]-[47]. Note that the notation used for describing the operating modes of the MOSFET is the one employed when the transistor is conceived as an amplifier. In the second solution, a Linear Power Amplifier (LPA) delivers the AC signal whereas a DC-DC power converter provides the DC bias component. Then, the AC signal is combined with the DC component with a bias-T [Fig. 4(b)]. The use of this kind of HB-LED driver for VLC is reported in [7], [13], [21]-[25] and [42]-[45]. The problem is that both HB-LED drivers jeopardize one of the main advantages of HB-LED lighting: the high power efficiency. This issue has been pointed out as one of the major bottlenecks of VLC in [7], [10] and [47]. Note that LPAs such as class A or B hardly reach an energy efficiency $40 \%$ when reproducing modern modulation schemes.

\section{E. Power Electronics Role and Objective Definition}

Once the fundamentals of VLC have been introduced, it is clear that it is an application with great potential. Using efficient modulation schemes instead of pulse-based waveforms is the preferred approach due to the high data rates achieved. However, the low power efficiency provided by the VCL transmitters that reproduce such schemes jeopardizes the deployment of this technology. It is task of power electronics to make VLC viable in terms of power efficiency [48].

This paper aims to alleviate the trade-off between power and

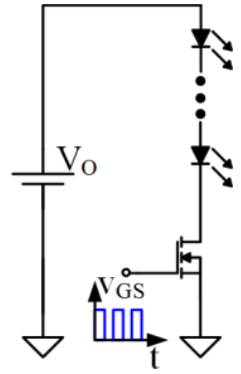

(a)

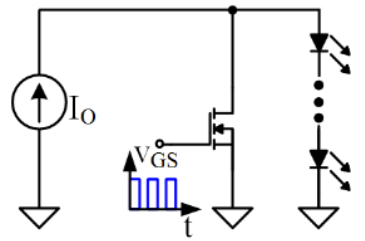

(b)
Fig. 3. HB-LED drivers for reproducing pulse-based modulation schemes: (a) MOSFET in series with the HB-LED string. (b) MOSFET in parallel with the HB-LED string.

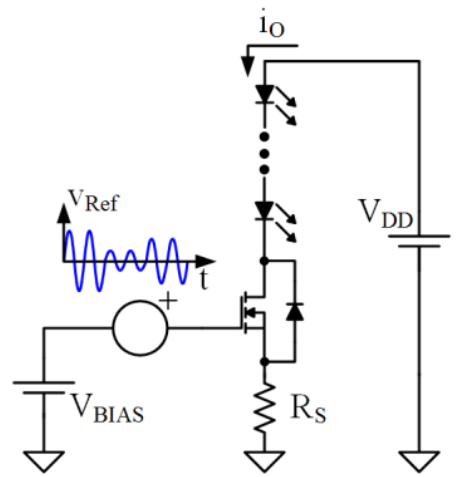

(a)

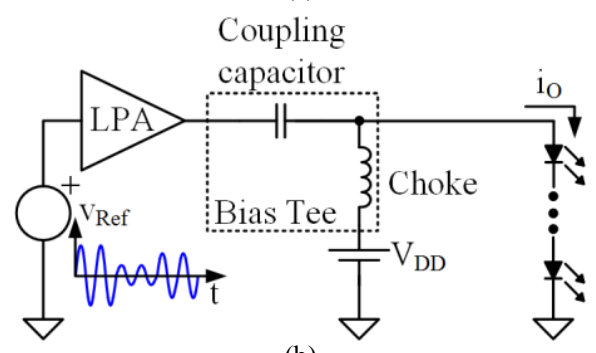

(b)

Fig. 4. VLC drivers for efficient modulation schemes: (a) MOSFET operating in linear mode. (b) Approach based on the use of a LPA.

communication efficiency by reproducing single-carrier digital modulation schemes with a DC-DC power converter [49], thus avoiding the use of power inefficient HB-LED drivers employed for VLC so far (i.e., circuits depicted in Fig. 4). This modulation family has already been proposed for VLC and their benefits have been demonstrated in [23] and [50]-[57]. Since the method presented in this work is fully based on the use of DC-DC power converters (i.e., power efficient approach), the target is to improve the results achieved in [37] and [39] (i.e., power efficient approach reproducing an inefficient modulation scheme).

\section{Single-CARRIER Digital ModUlation SCHEMES}

Single-carrier digital modulation schemes are a family of efficient modulation schemes that are based on the use of a sinusoidal waveform (i.e., the carrier) to transmit information. In the particular case of VLC, the light intensity signal $(\mathrm{s}(\mathrm{t}))$ is made up of a sinusoidal waveform $\left(\mathrm{s}_{\mathrm{AC}}(\mathrm{t})\right)$ and a DC component $\left(\mathrm{s}_{\mathrm{DC}}\right)$ that fulfill the communication and lighting functionalities, 
respectively:

$$
\begin{aligned}
& s(t)=s_{A C}(t)+s_{D C}= \\
& A_{S}(t) \cdot \cos \left(2 \pi f_{O} t+\phi_{s}(t)\right)+s_{D C},
\end{aligned}
$$

where $f_{O}$ is the carrier frequency. There are two parameters of $\mathrm{s}_{\mathrm{AC}}(\mathrm{t})$ that can be changed dynamically to transmit information: the amplitude $\left(\mathrm{A}_{S}(\mathrm{t})\right)$ and the phase $\left(\phi_{S}(\mathrm{t})\right)$. When the amplitude keeps constant and the phase changes, the modulation scheme is called Phase-Shift Keying (PSK). On the other hand, when the amplitude changes and the phase keeps constant, the modulation scheme is called Amplitude-Shift Keying (ASK). In order to increase the amount of transmitted information, a hybrid modulation scheme can be reproduced: Quadrature Amplitude Modulation (QAM). This modulation scheme transmits information both in the amplitude and in the phase by changing these two parameters independently. Carrier-less Amplitude and Phase modulation (CAP) is another single-carrier digital modulation scheme that sends information both in the amplitude and in the phase. In practice, it is closely similar to QAM because the only difference is the interpretation of the in-phase and quadrature components [58]. Therefore, although it can be reproduced using the method presented in this work, it will not be mentioned along the rest of the paper. In addition, PSK and ASK are particular cases of QAM. Then, the rest of the paper is focused on reproducing the last one.

It is important to note that PSK, ASK and QAM have a higher spectral efficiency than the Variable Pulse Position Modulation (VPPM) scheme reproduced in [37] and [39]. Therefore, these single-carrier digital modulation schemes provide higher data rates using the same bandwidth, being QAM the one that achieves the highest spectral efficiency. The demonstration of these statements can be found in several digital wireless communication references [59]-[62]. The next example clearly shows that single-carrier digital modulation schemes are more efficient than VPPM. In VPPM, the number of symbols is the number of slots in which the symbol period ( $\left.\mathrm{T}_{\mathrm{SYM}}\right)$ is divided. In each one of these slots, a pulse can be transmitted. The VPPM scheme reproduced in [37] and [39] considers two symbols: the pulse can be placed at the beginning or at the end of the symbol period. Consequently, each VPPM symbol transmits 1 bit. Note that the number of bits per symbol is equal to $\log _{2}(\mathrm{NS})$, where NS is the number of symbols. In order to make a fair comparison between VPPM, PSK, ASK and QAM, it is assumed that the transmitter is able to reproduce a fixed number of amplitudes and phases. In this sense, four amplitudes and four phases are considered to exemplify the statement. According to this assumption, there are four possible symbols in the case of PSK (i.e., four different phases) and in the case of ASK (i.e., four different amplitudes). As a results, each PSK or ASK symbol transmits 2 bits. In the case of QAM there are sixteen possible symbols that are obtained by combining the four possible amplitudes and the four possible phases. Therefore, each QAM symbol transmits 4 bits. Obviously, $\mathrm{T}_{\mathrm{SYM}}$ should be equal for all modulation schemes to make a fair analysis. Since the number of symbols transmitted by each modulation scheme is the same during a certain time span and the number of bits per symbol is higher in the case of QAM, ASK and PSK, the single-carrier digital modulation schemes transmit more bits than VPPM (i.e., the bit rate achieved is higher). In addition, QAM provides the highest bit rate. Fig. 5 shows an arbitrary sequence where three symbols are transmitted. It is considered that $\mathrm{T}_{\mathrm{SYM}}$ is equal to $2 \cdot \mathrm{T}_{\mathrm{O}}$ for the representation (where $\mathrm{T}_{\mathrm{O}}$ is the carrier period). According to the previous explanation, $3 \cdot \mathrm{T}_{\mathrm{SYM}}$ implies the transmission of twelve bits in the case of QAM and three bits in the case of VPPM. Both in the PSK and ASK cases, six bits are transmitted.

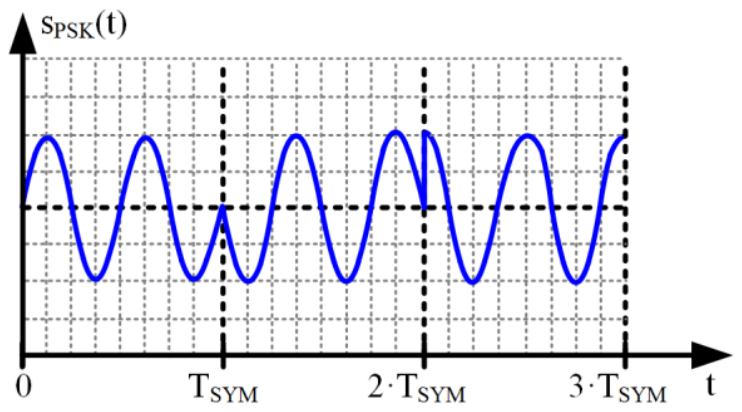

(a)

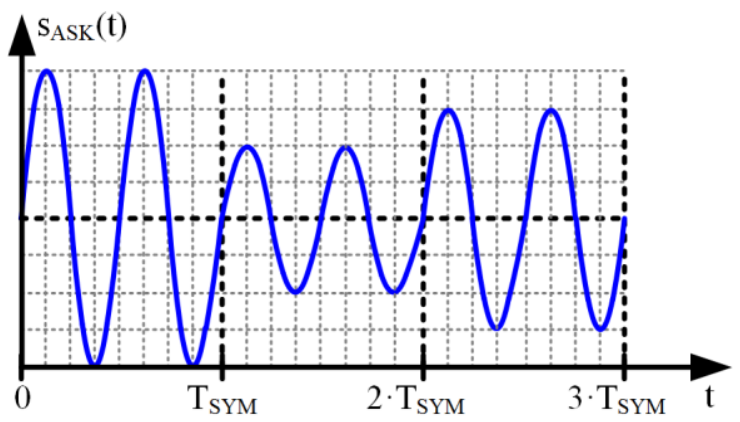

(b)

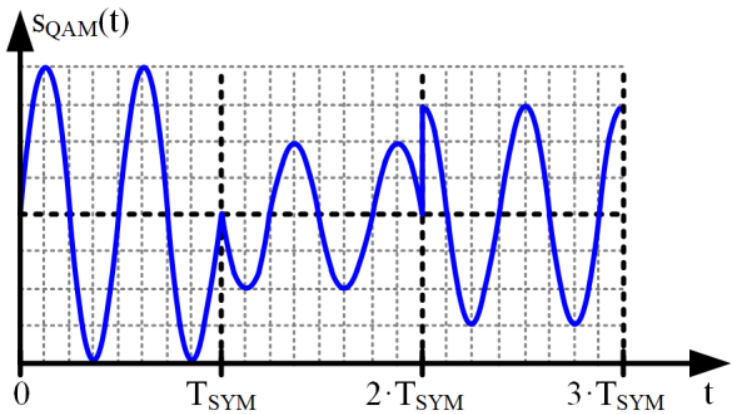

(c)

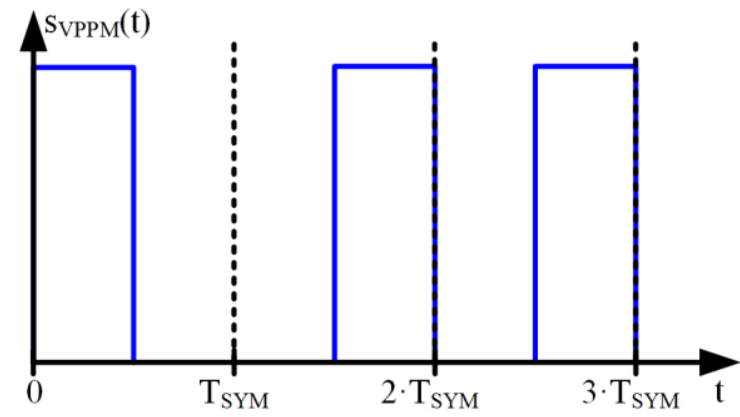

(d)

Fig. 5. Light intensity waveforms for the four modulation schemes considered in the example: (a) PSK. (b) ASK. (c) QAM. (d) VPPM. 


\section{REQUIREMENTS AND INITIAL METHODS FOR REPRODUCING SINGLE-CARRIER DIGITAL MODULATION \\ SCHEMES WITH DC-DC POWER CONVERTERS}

According to (1), the VLC transmitter must provide a sinusoidal light intensity waveform (i.e., $\mathrm{s}_{\mathrm{AC}}(\mathrm{t})$ ) with a $\mathrm{DC}$ component (i.e., $\mathrm{s}_{\mathrm{DC}}$ ). Moreover, it must be able to change the sinusoid amplitude (i.e., $A_{S}(t)$ ) and phase (i.e., $\phi_{S}(t)$ ) to reproduce a QAM scheme, and, in addition, $\mathrm{S}_{\mathrm{DC}}$ must be modifiable to perform dimming. Fig. 6 shows how to obtain the desired light intensity emitted by a HB-LED string (i.e., generating $s(t))$ by controlling the output voltage of the HBLED driver $\left(\mathrm{v}_{\mathrm{O}}(\mathrm{t})\right)$. If the voltage is higher than a certain value denoted as $\mathrm{V}_{\mathrm{F}}, \mathrm{s}_{\mathrm{AC}}(\mathrm{t})$ is proportional to the $\mathrm{AC}$ component of vo(t). Therefore, the DC-DC power converter must be able to reproduce a sinusoidal output voltage waveform $\left(\mathrm{v}_{\mathrm{O}-\mathrm{AC}}(\mathrm{t})\right)$ with a certain DC component (VO-DC) in order to obtain the desired $s(t)$. Note that the amplitude $\left(A_{v}(t)\right)$, the phase $\left(\phi_{v}(t)\right)$ and $v_{O-D C}$ should be modifiable by the DC-DC power converter control strategy. Then, the required $v_{0}(t)$ is defined as:

$$
\begin{aligned}
& v_{O}(t)=v_{O-A C}(t)+v_{O-D C}= \\
& \quad A_{v}(t) \cos \left(2 \pi f_{O} t+\phi_{v}(t)\right)+v_{O-D C} .
\end{aligned}
$$

\section{A. Method Based on the Pulse-Width Modulation Technique}

A well-known method to reproduce a time-varying output voltage (such as (2)) is to perform variations of the DC-DC power converter duty cycle (d). According to this method, which is referred as Pulse-Width Modulation (PWM), the pulses width of the square waveform determines vo(t). This approach is employed in several applications such as inverters [63] and Class-D audio amplifiers [64]. In addition, it is widely used to increase the efficiency of Radio Frequency Power Amplifiers (RFPAs) through the Envelope Tracking (ET) and Envelope Elimination and Restoration (EER) techniques [65][69], where DC-DC power converters with bandwidths of several $\mathrm{MHz}$ are addressed.
It is important to note that the bandwidth of $s(t)$ and $v_{0}(t)$ are the same. Then, according to the Nyquist-Shannon sampling theorem, the switching frequency ( $f_{\mathrm{Sw}}$ ) must be at least two times higher than the maximum frequency ( $\mathrm{f}_{\mathrm{S}-\mathrm{MAX}}$ ) of the desired $s(t)$. In the case of single-carrier digital modulation schemes, since the carrier amplitude and phase change over the time, the spectrum magnitude differs from a delta function centered at $f_{0}$. Moreover, the lower the $T_{\mathrm{SYM}}$ value, the higher the $\mathrm{f}_{\mathrm{S}-\mathrm{MAX}}$ value. Note that reducing $\mathrm{T}_{\mathrm{SYM}}$ increases the bit rate, but also the bandwidth. For this reason, in order to properly select $f_{\mathrm{SW}}$, a signal spectrum analysis must be carried out. However, the signal spectrum modeling requires an extensive mathematical analysis that is out of the scope of this paper. Fig. 7 shows an example of the $\mathrm{s}(\mathrm{t})$ spectrum magnitude (i.e., $|\mathrm{s}(\mathrm{f})|$ ) considering a 64-QAM scheme (i.e., QAM scheme with 64 symbols) with $\mathrm{T}_{\mathrm{SYM}}$ equal to $3 \cdot \mathrm{T}_{\mathrm{O}}$. This means that a symbol is represented by three cycles of the carrier. It is assumed that the signal bandwidth is equal to the first null above $f_{0}$, which is placed at $\mathrm{f}_{\mathrm{O}}+1 / \mathrm{T}_{\mathrm{SYM}}$. Under these conditions $\mathrm{f}_{\mathrm{S}-\mathrm{MAX}}$ is equal to $1.33 \cdot f_{0}$. Consequently, the theoretical minimum value of $f_{S w}$ is $2.66 \cdot f_{0}$. However, such a low $f_{S w}$ value is unattainable in practice because the switching frequency components and their sidebands distort the signal. As a result, a careful filter design and a $\mathrm{f}_{\mathrm{SW}}$ value between $3 \cdot \mathrm{f}_{\mathrm{S}-\mathrm{MAX}}$ and $6 \cdot \mathrm{f}_{\mathrm{S}-\mathrm{MAX}}$ are mandatory $[70]$.

The PWM technique was applied in HB-LED drivers for VLC in two recent researches. A square voltage waveform with a maximum frequency component of $1 \mathrm{MHz}$ is reproduced in [48] using $\mathrm{f}_{\mathrm{Sw}}$ equal to $5 \mathrm{MHz}$. In the case of [71], the reproduction of a communication signal with a maximum frequency component equal to $3 \mathrm{MHz}$ is performed by using $\mathrm{f}_{\mathrm{SW}}$ equal to $10 \mathrm{MHz}$.

The research target is to reproduce a single-carrier digital modulation scheme keeping $\mathrm{f}_{\mathrm{SW}}$ as low as possible to minimize the switching losses. Therefore, an approach that requires a lower $\mathrm{f}_{\mathrm{SW}}$ is desirable. As will be explained in Section V, $\mathrm{f}_{\mathrm{SW}}$ is equal to $f_{O}$ in the case of the method which is going to be presented in this paper.

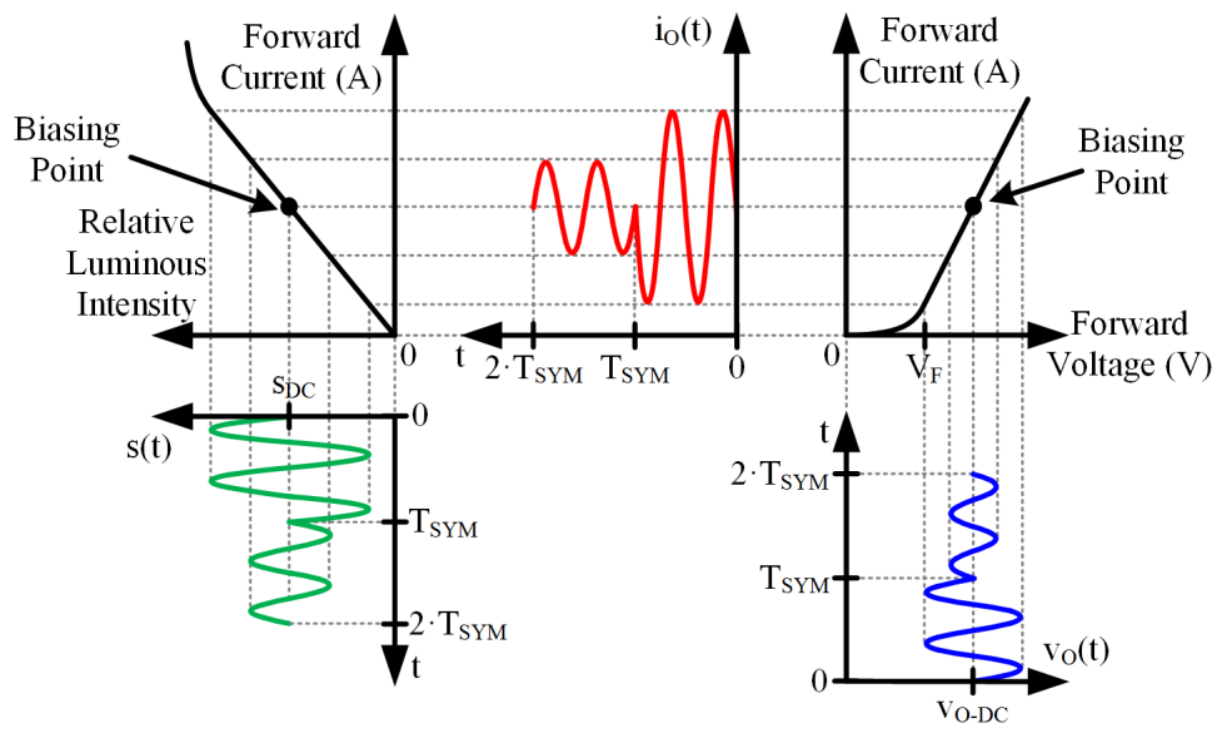

Fig. 6. Modulation of the amplitude and the phase of the light intensity emitted by a HB-LED string performed by controlling the output voltage of the HB-LED driver. 


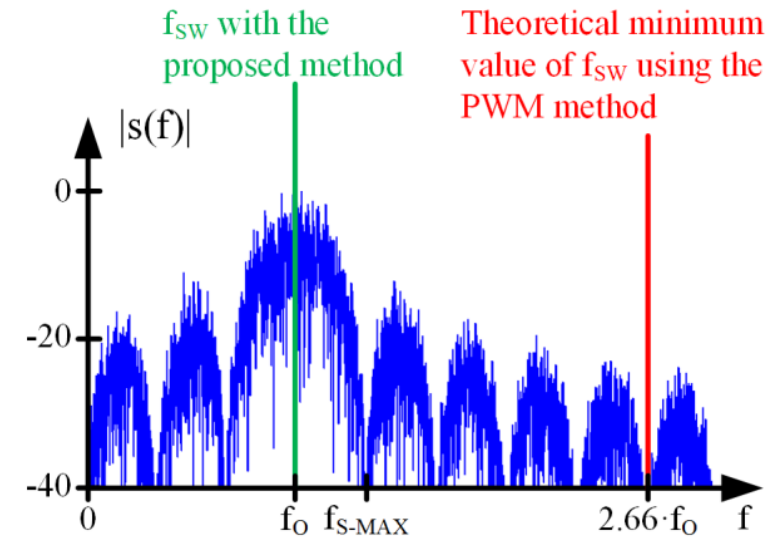

Fig. 7. Example of a $\mathrm{s}(\mathrm{t})$ spectrum magnitude when considering a 64-QAM scheme and $\mathrm{T}_{\mathrm{SYM}}$ equal to $3 \cdot \mathrm{T}_{\mathrm{O}}$. It is highlighted the required $\mathrm{f}_{\mathrm{SW}}$ when applying the method proposed in this paper and the method based on the PWM technique.

\section{B. First Approach for Controlling the First Switching Harmonic}

The first approach of the proposed method consists in using a buck converter that reproduces a single-carrier digital modulation scheme by controlling the first switching harmonic of the output voltage ripple. As Fig. 8(a) shows, a $m^{\text {th }}$-order low-pass filter design is employed. Fig. 8(b) shows the equivalent circuit after considering $v_{X}(t)$ as an ideal pulse voltage source. Then, the circuit is represented as a pulse voltage source applied to a $m^{\text {th }}$-order low-pass filter [see Fig. $8(\mathrm{c})]$, where $\mathrm{f}_{\mathrm{C}}$ is the cut-off frequency of the filter). Differently from the traditional buck converter design which aims to remove all the switching harmonics of $v_{X}(t)$ (i.e., $f_{C}<<f_{S W}$ to attenuate the frequency components centered at $\mathrm{f}_{\mathrm{SW}}, 2 \cdot \mathrm{f}_{\mathrm{Sw}}$, $3 \cdot f_{\text {Sw }}$, etc.), the filter of the buck considered for the method proposed in this paper passes the DC component and the first switching harmonic (i.e., $\mathrm{f}_{\mathrm{SW}}<\mathrm{f}_{\mathrm{C}}<2 \cdot \mathrm{f}_{\mathrm{SW}}$ ). A proper method to design the filter is detailed in Section V.C.

In order to reduce the mathematical complexity of the explanation, it is considered that the pulses width and their delay with respect to the beginning of the switching period $\left(\gamma \cdot T_{\mathrm{SW}}\right.$, where $\mathrm{T}_{\mathrm{SW}}$ is the switching period) do not change over time. Then, $\mathrm{v}_{\mathrm{X}}(\mathrm{t})$ can be expressed as a function of its harmonics by using the Fourier analysis:

$$
\begin{aligned}
& v_{X}(t)=d V_{G}+ \\
& \sum_{k=1}^{\infty} \frac{2 V_{G}}{k \pi} \sin (k \pi d) \cos \left(2 \pi k f_{S W} t-\gamma k 2 \pi\right) .
\end{aligned}
$$

Taking into account the proposed filter design, $v_{O}(t)$ is equal to the DC component and the first switching harmonic of $\mathrm{v}_{\mathrm{X}}(\mathrm{t})$ (now redefining $\mathrm{v}_{\mathrm{O}-\mathrm{DC}}$ and $\mathrm{v}_{\mathrm{O}-\mathrm{AC}}(\mathrm{t})$ ) with a certain delay $\left(\mathrm{t}_{\mathrm{FIL}}\right)$ due to the nature of the filter:

$$
\begin{aligned}
& v_{O}(t)=v_{O-D C}+v_{O-A C}(t)=d V_{G}+ \\
& \frac{2 V_{G}}{\pi} \sin (\pi d) \cos \left(2 \pi f_{S W}\left(t-t_{F I L}\right)-\gamma 2 \pi\right) .
\end{aligned}
$$

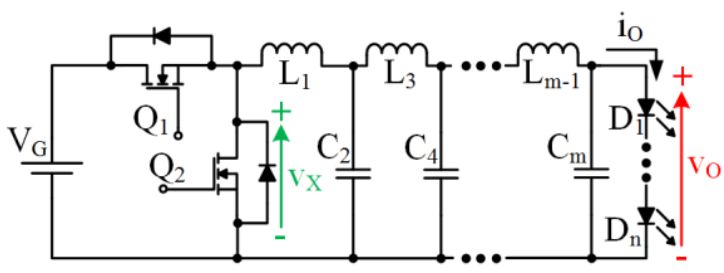

(a)

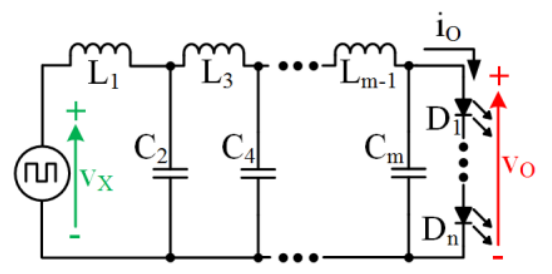

(b)

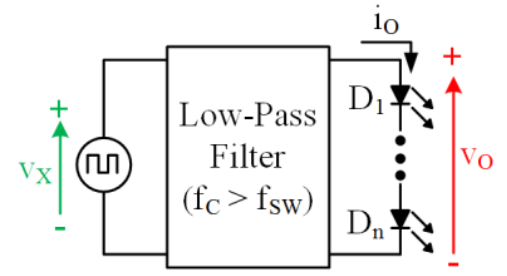

(c)

Fig. 8. Synchronous buck converter that reproduces single-carrier digital modulation schemes by controlling the first switching harmonic of its output voltage ripple: (a) Schematic considering a $m^{\text {th }}$-order low-pass filter and a string of $n$ HB-LEDs. (b) Equivalent circuit after considering $v_{\mathrm{X}}(\mathrm{t})$ as an ideal voltage source. (c) Simplified circuit.

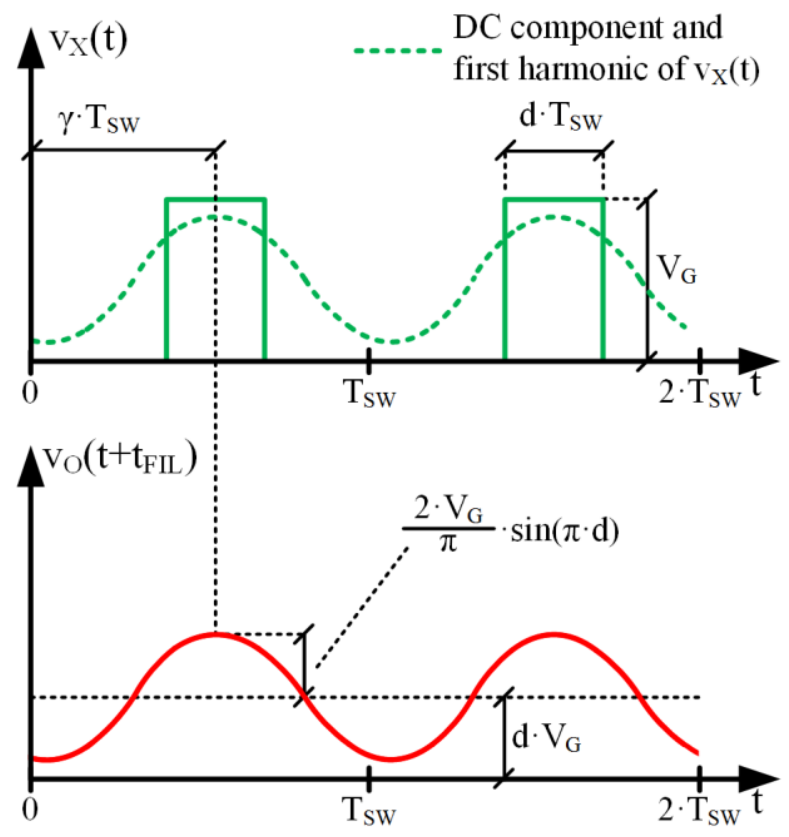

Fig. 9. Drain to source voltage of $\mathrm{Q}_{2}$ (i.e., switch-node voltage of the buck converter) and output voltage of the synchronous buck converter that reproduces single-carrier digital modulation schemes by controlling the first switching harmonic of its output voltage ripple. Main control parameters are included (i.e., $\gamma$ and d). Note that the output voltage representation cancels the filter delay $\left(t_{\mathrm{FIL}}\right)$ to facilitate the understanding. Moreover, the dashed line represents the first harmonic plus the DC component of the switch-node voltage. 
Note that this delay does not imply any negative effect for the transmission. According to (4) and as Fig. 9 shows, the amplitude and phase of $\mathrm{v}_{\mathrm{O}-\mathrm{AC}}(\mathrm{t})$ can be controlled by using the duty cycle and the phase of $v_{X}(t)($ i.e., $-\gamma \cdot 2 \cdot \pi)$, respectively. The problem is that this approach does not enable the implementation of the desired VLC transmitter because it is not able to change the amplitude of $v_{0-A C}(t)$ without modifying $v_{O}$ DC. Therefore, the approach must be improved to be able to control independently the amplitude, the phase and the DC component of $v_{O}(t)$. A possible solution is detailed in Section V.

\section{DC-DC POWER CONVERTER FOR REPRODUCING SINGLE- CARRIER Digital MODULATION SCHEMES FOR VLC BY CONTROLLING THE FIRST SWITCHING HARMONIC}

\section{A. Theoretical Base of the Definitive Approach for Controlling the First Switching Harmonic}

The definitive approach for using the first switching harmonic of the output voltage ripple to reproduce singlecarrier digital modulation schemes is based on a mathematical property that is explained in this section. Consider two sinusoidal waveforms, $\mathrm{v}_{\mathrm{A}}(\mathrm{t})$ and $\mathrm{v}_{\mathrm{B}}(\mathrm{t})$, that have the same amplitude (M) and frequency (i.e., $f_{0}$ ) but different phases ($\gamma_{1} \cdot 2 \cdot \pi$ and $-\gamma_{2} \cdot 2 \cdot \pi$, respectively):

$$
\begin{aligned}
& v_{A}(t)=M \cos \left(2 \pi f_{O} t-\gamma_{1} 2 \pi\right), \\
& v_{B}(t)=M \cos \left(2 \pi f_{O} t-\gamma_{2} 2 \pi\right) .
\end{aligned}
$$

Although $\gamma_{1}$ and $\gamma_{2}$ vary within 0 and 1 limits, as it will be justified later, the maximum difference allowed between them is 0.5 . In addition, it is assumed that $\gamma_{2}$ is higher or equal to $\gamma_{1}$. It is known that the sum of these two sinusoidal waveforms is equal to a third sinusoidal waveform (i.e., $\left.\mathrm{v}_{\mathrm{C}}(\mathrm{t})\right)$ which has the same frequency:

$$
\begin{aligned}
& v_{C}(t)=v_{A}(t)+v_{B}(t)= \\
& 2 M \cos (\alpha \pi) \cos \left(2 \pi f_{O} t-\beta 2 \pi\right),
\end{aligned}
$$

where $\alpha$ is the phase-shift between $\mathrm{v}_{\mathrm{B}}(\mathrm{t})$ and $\mathrm{v}_{\mathrm{A}}(\mathrm{t})$ divided by $2 \cdot \pi$ and $\beta$ is the absolute value of the mean phase of $\mathrm{v}_{\mathrm{A}}(\mathrm{t})$ and $\mathrm{v}_{\mathrm{B}}(\mathrm{t})$ divided by $2 \cdot \pi$ (i.e., the mean value of $\gamma_{1}$ and $\gamma_{2}$ ):

$$
\begin{aligned}
& \alpha=\frac{\gamma_{2} 2 \pi-\gamma_{1} 2 \pi}{2 \pi}=\gamma_{2}-\gamma_{1}, \\
& \beta=\frac{\gamma_{1} 2 \pi+\gamma_{2} 2 \pi}{2(2 \pi)}=\frac{\gamma_{1}+\gamma_{2}}{2} .
\end{aligned}
$$

According to (7), $\alpha$ determines the amplitude of $\mathrm{v}_{\mathrm{C}}(\mathrm{t})$. When $\alpha$ is 0 (i.e., the phase-shift is 0 radian), the maximum amplitude (i.e., $2 \cdot \mathrm{M}$ ) is reached. On the other hand, when $\alpha$ is 0.5 (i.e., the phase-shift is $\pi$ radian), the amplitude is 0 . Then, the higher the phase-shift, the lower the amplitude of $\mathrm{v}_{\mathrm{C}}(\mathrm{t})$. It is important to note that when $\alpha$ is higher than 0.5 (i.e., the phaseshift is higher than $\pi$ radians), the sign of $\mathrm{v}_{\mathrm{C}}(\mathrm{t})$ changes. Therefore, it is stablished that $\alpha$ must range between 0 and 0.5 limits in order to avoid the phase modification.
Considering (7), $\beta$ determines the phase of $\mathrm{v}_{\mathrm{C}}(\mathrm{t})$. For instance, if the phases of $\mathrm{v}_{\mathrm{A}}(\mathrm{t})$ and $\mathrm{v}_{\mathrm{B}}(\mathrm{t})$ are $-\pi / 4$ and $-3 \cdot \pi / 4$, respectively (i.e., $\gamma_{1}$ and $\gamma_{2}$ are equal to $1 / 8$ and $3 / 8$, respectively), the phase of $\mathrm{v}_{\mathrm{C}}(\mathrm{t})$ is $-\pi / 2$ (i.e., $\beta$ is equal to $1 / 4$ ). Note that $\beta$ varies within 0 and 1 limits.

Fig. 10(a) shows $v_{C}(t)$ for certain values of $\alpha$ and $\beta$ (i.e., $\alpha=$ $\alpha_{1}$ and $\beta=\beta_{1}$ ). Fig. 10(b) demonstrates that the amplitude of $\mathrm{v}_{\mathrm{C}}(\mathrm{t})$ rises as $\alpha$ falls (for $\alpha=\alpha_{2}$ where $\alpha_{2}<\alpha_{1}$ ). On the other hand, Fig. 10(c) shows that the phase of $v_{\mathrm{C}}(\mathrm{t})$ falls as $\beta$ increases (for $\beta=\beta_{2}$ where $\beta_{2}>\beta_{1}$ ).

The conclusion is that a sinusoidal waveform whose amplitude and phase must be controllable independently, can be generated by the sum of two sinusoidal waveforms with both

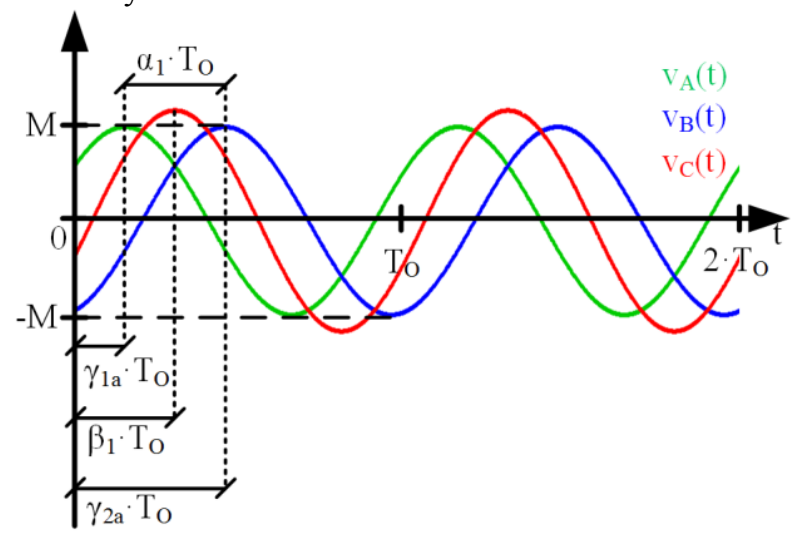

(a)

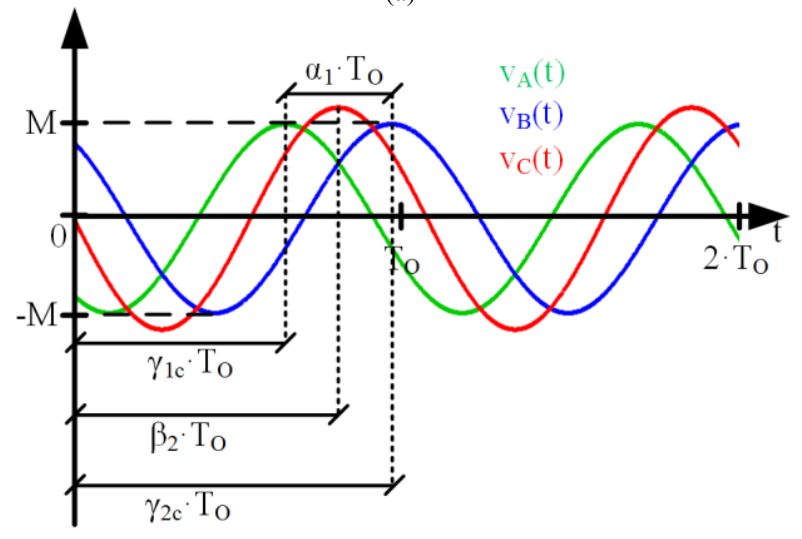

(b)

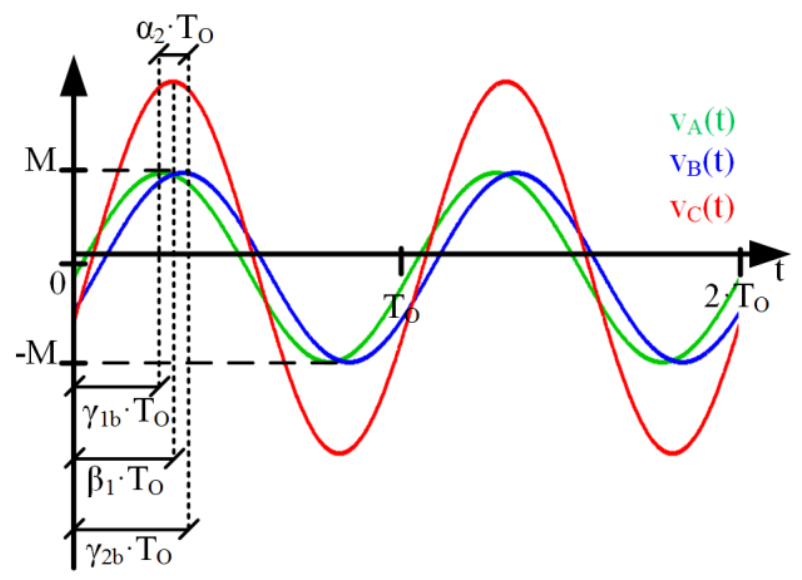

(c)

Fig. 10. Sum of two sinusoidal waveforms with both the same amplitude and the same frequency but different phase: (a) Initial conditions. (b) Effect of decreasing $\alpha$. (c) Effect of increasing $\beta$. 
the same amplitude and the same frequency by changing their phases.

\section{B. Topology and Operating Principle}

The definitive approach for controlling the first switching harmonic of the output voltage ripple to reproduce a singlecarrier digital modulation scheme is based on the use of a twophase synchronous buck converter. As in the case of singlephase synchronous buck converter approach, a $m^{\text {th }}$-order lowpass filter design is employed [see Fig. 11(a)]. Note that $f_{S W}, d$ and the input voltage $\left(\mathrm{V}_{\mathrm{G}}\right)$ of each phase is the same. Fig. 11(b) shows the equivalent circuit after considering $v_{x_{1}}(t)$ and $v_{x_{2}}(t)$ as ideal pulse voltage sources (where $v_{X 1}(t)$ and $v_{X 2}(t)$ are the switch-node voltages). Fig. 11(c) can be obtained from Fig. 11(b) by applying superposition theorem, Thevenin's theorem and considering that $\mathrm{L}_{1 \mathrm{~B}}$ is equal to $\mathrm{L}_{1 \mathrm{~A}}$. Under these conditions, $\mathrm{L}_{1}$ is equal to $0.5 \mathrm{~L}_{1 \mathrm{~A}}$. After these simplifications, the circuit can be seen as the sum of the two pulse voltage sources and, therefore, as a three-level voltage source $\left(\mathrm{v}_{\mathrm{T}}(\mathrm{t})\right)$ applied to a $m^{\text {th }}$ order low-pass filter [see Fig. 11(d)]. As in Section IV.B, it is considered that the filter passes the DC component and the first switching harmonic (i.e., $\mathrm{f}_{\mathrm{SW}}<\mathrm{f}_{\mathrm{C}}<2 \cdot \mathrm{f}_{\mathrm{SW}}$ ).

The two-phase synchronous buck converter control method for obtaining the desired $\mathrm{v}_{\mathrm{O}}(\mathrm{t})$ is based on the mathematical property detailed in Section V.A. Fig. 12 shows the main voltage waveforms involved in the process.

In order to facilitate the understanding, it is considered that the pulses width and their delay with respect to the beginning of the switching period (i.e., $\gamma_{1} \cdot \mathrm{T}_{\mathrm{SW}}$ and $\gamma_{2} \cdot \mathrm{T}_{\mathrm{Sw}}$ ) do not change over time. Then, $v_{X 1}(t), v_{X 2}(t)$ and $v_{T}(t)$ can be expressed as a function of their harmonics by using the Fourier analysis:

$$
\begin{aligned}
& v_{X 1}(t)=d V_{G}+ \\
& \sum_{k=1}^{\infty} \frac{2 V_{G}}{k \pi} \sin (k \pi d) \cos \left(2 \pi k f_{S W} t-\gamma_{1} k 2 \pi\right) \\
& v_{X 2}(t)=d V_{G}+ \\
& \sum_{k=1}^{\infty} \frac{2 V_{G}}{k \pi} \sin (k \pi d) \cos \left(2 \pi k f_{S W} t-\gamma_{2} k 2 \pi\right) \\
& v_{T}(t)=\frac{1}{2}\left(v_{X 1}(t)+v_{X 2}(t)\right)=d V_{G}+ \\
& \sum_{k=1}^{\infty} \frac{2 V_{G}}{k \pi} \sin (k \pi d) \cos (k \pi \alpha) \cos \left(2 \pi k f_{S W} t-\beta k 2 \pi\right)
\end{aligned}
$$

Since $v_{T}(t)$ is the sum of $v_{X_{1}}(t)$ and $v_{X 2}(t)$ multiplied by 0.5 , each harmonic of $\mathrm{v}_{\mathrm{T}}(\mathrm{t})$ includes the sum of the respective harmonic content of $\mathrm{v}_{\mathrm{X} 1}(\mathrm{t})$ plus the respective harmonic content of $\mathrm{v}_{\mathrm{X} 2}(\mathrm{t})$. The relationship between the DC-DC power converter control method and the previously explained mathematical property arises here. In this case, the two sinusoids that are summed (i.e., $\mathrm{v}_{\mathrm{A}}(\mathrm{t})$ and $\mathrm{v}_{\mathrm{B}}(\mathrm{t})$ in Section V.A) are the first switching harmonic of $\mathrm{v}_{\mathrm{X} 1}(\mathrm{t})$ and $\mathrm{v}_{\mathrm{X} 2}(\mathrm{t})$, in this case multiplied by 0.5 . The result (i.e., $v_{C}(t)$ in Section V.A) is the first switching harmonic of $v_{\mathrm{T}}(t)$, whose amplitude and phase can be modified by controlling the phase of $v_{X_{1}}(t)$ and the phase of $\mathrm{v}_{\mathrm{X} 2}(\mathrm{t})$. As in Section V.A, $\alpha$ and $\beta$ can be used to control the amplitude and the phase, respectively. Now, $\alpha$ is the phase-shift between the first switching harmonic of $\mathrm{v}_{\mathrm{X} 2}(\mathrm{t})$ and $\mathrm{v}_{\mathrm{X}_{1}}(\mathrm{t})$ divided by $2 \cdot \pi$. Moreover, $\beta$ is the absolute value of the mean phase of $v_{X_{1}}(t)$ and $v_{X_{2}}(t)$ divided by $2 \cdot \pi$ (i.e., the mean value of $\gamma_{1}$ and $\gamma_{2}$ ). Note that the phase origin is defined at the instants when a new switching period begins (i.e., $\mathrm{t}=0, \mathrm{t}=\mathrm{T}_{\mathrm{Sw}}, \mathrm{t}=$ $2 \cdot \mathrm{T}_{\mathrm{SW}}$, etc.).

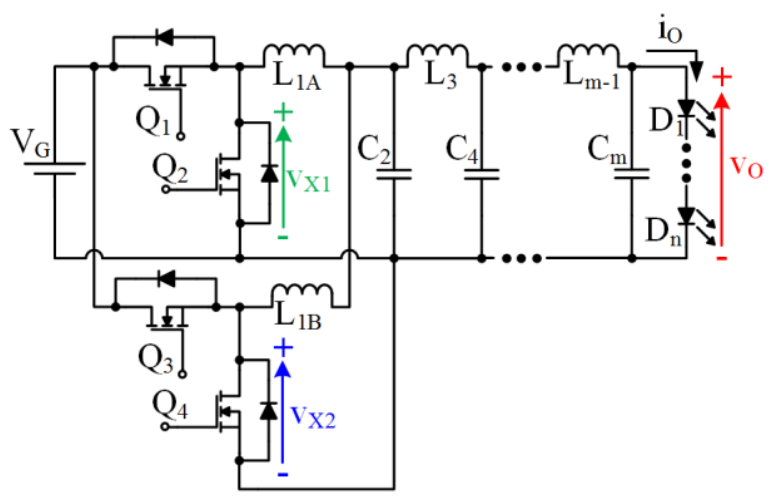

(a)

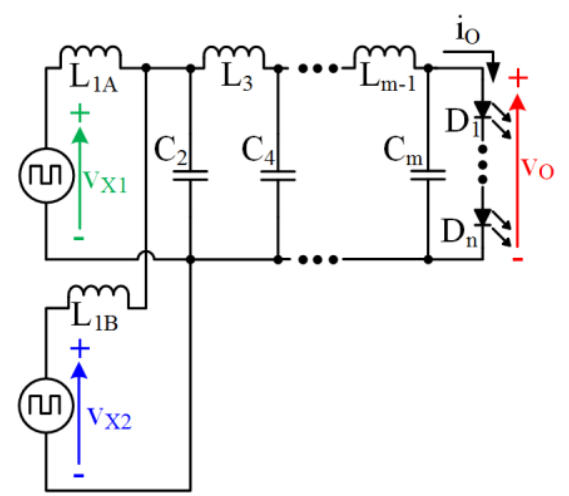

(b)

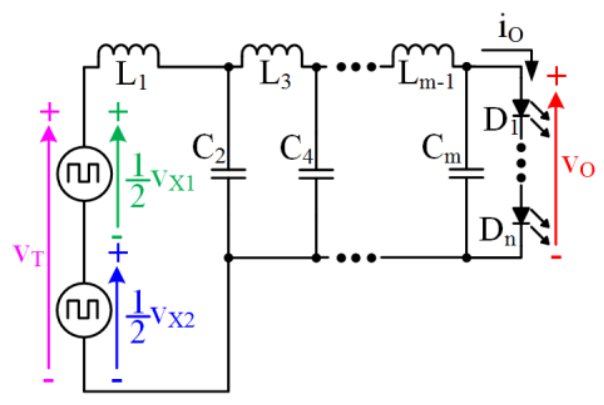

(c)

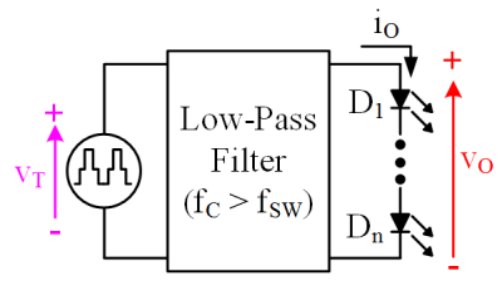

(d)

Fig. 11. Two-phase synchronous buck converter that reproduces single-carrier digital modulation schemes by controlling the first switching harmonic of its output voltage ripple: (a) Schematic considering a $m^{\text {th }}$-order low-pass filter and a string of $n$ HB-LEDs. (b) Equivalent circuit after considering $\mathrm{v}_{\mathrm{X} 1}(\mathrm{t})$ and $\mathrm{v}_{\mathrm{X} 2}(\mathrm{t})$ as ideal voltage sources. (c) Equivalent circuit after applying superposition theorem, Thevenin's theorem and considering that $\mathrm{L}_{1 \mathrm{~B}}$ is equal to $\mathrm{L}_{1 \mathrm{~A}}$. (d) Simplified circuit. 
Taking into account the proposed filter design, $v_{0}(t)$ is equal to the DC component and the first switching harmonic of $\mathrm{v}_{\mathrm{T}}(\mathrm{t})$ with the delay introduced by the filter (i.e., $t_{\mathrm{FIL}}$ ):

$$
\begin{aligned}
& v_{O}(t)=v_{O-D C}+v_{O-A C}(t)=d V_{G}+ \\
& \frac{2 V_{G}}{\pi} \sin (\pi d) \cos (\pi \alpha) \cos \left(2 \pi f_{S W}\left(t-t_{F I L}\right)-\beta 2 \pi\right) .
\end{aligned}
$$

Then, $d$ can be used to fix $v_{0}$-DC. After that, $\alpha$ and $\beta$ can be
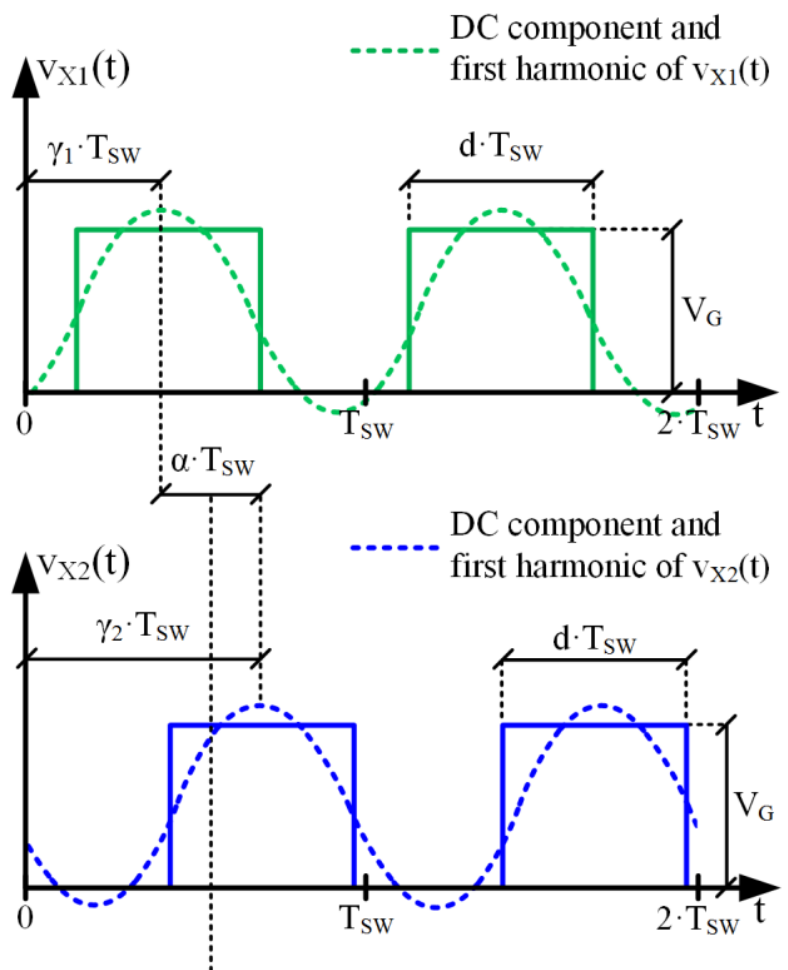

DC component and

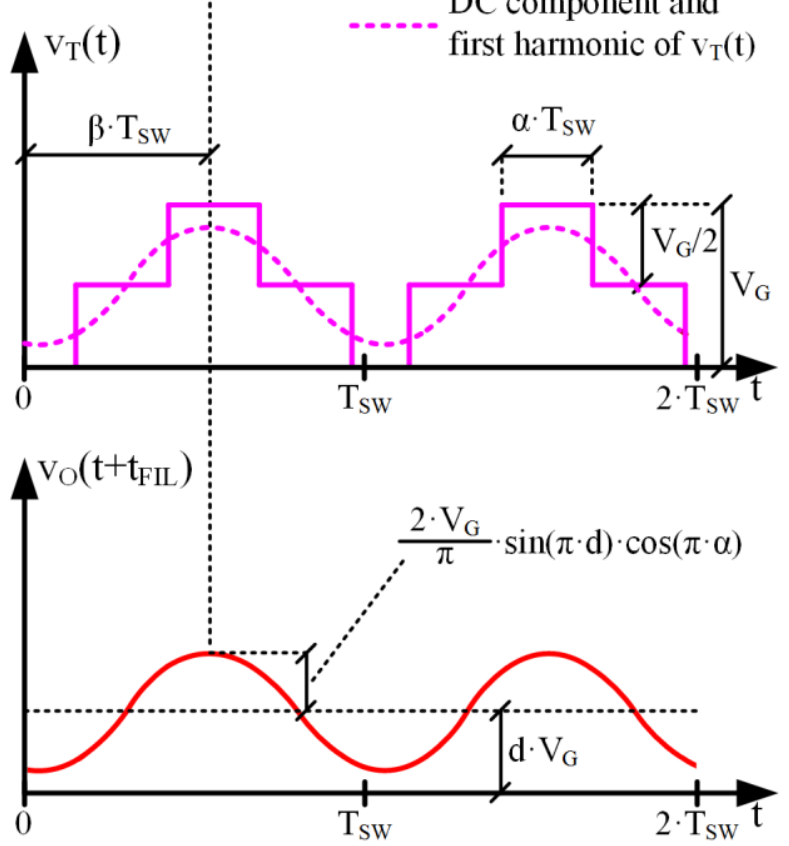

Fig. 12. Main voltage waveforms involved in the control method of the twophase synchronous buck converter. The main parameters of the control (i.e., $\gamma_{1}, \gamma_{2}, \alpha, \beta$ and d) are included. Note that the dashed lines represent the first harmonic plus the DC component of each waveform and the output voltage representation cancels the filter delay ( $\mathrm{t}_{\mathrm{FLL}}$ ) to facilitate the understanding. calculated in order to obtain the desired amplitude and the phase of $\mathrm{V}_{\mathrm{O}-\mathrm{AC}}(\mathrm{t})$. As a conclusion, $\mathrm{V}_{\mathrm{O}-\mathrm{DC}}$ complies with the lighting functionality whereas $\mathrm{V}_{\mathrm{O}-\mathrm{AC}}(\mathrm{t})$ performs the communication functionality. Obviously, the proposed method is also able to reproduce modulation schemes simpler than QAM. ASK can be performed by fixing the carrier phase and changing its amplitude (i.e., $\beta$ is a constant value and $\alpha$ is modified over time). Moreover, PSK can be reproduced by fixing the carrier amplitude and changing its phase (i.e., $\alpha$ is a constant value and $\beta$ is modified over time).

\section{Low-Pass Filter Design}

In order to exemplify the low-pass filter design process, the filter developed for the prototype detailed in Section VI is explained in this section. The DC component and the first switching harmonic of $\mathrm{v}_{\mathrm{T}}(\mathrm{t})$ constitute the part of the spectrum that must be maintained at the output of the DC-DC power converter. Therefore, the design target consists in removing the second and higher switching harmonics of $\mathrm{v}_{\mathrm{T}}(\mathrm{t})$. To evaluate the spectrum magnitude at the input of the filter (i.e., $\left|\mathrm{v}_{\mathrm{T}}(\mathrm{f})\right|$ ), some considerations must be taken into account. In order to generate different symbols by dynamically changing the amplitude and the phase of $v_{0}(t), \alpha$ and $\beta$ must change over time. As a consequence, and differently from the explanation given in Section V.B, changes of the $v_{X_{1}}(t)$ and $v_{X_{2}}(t)$ phases over time must be considered (i.e., variable time delay: $\gamma_{1}(\mathrm{t}) \cdot \mathrm{T}_{\mathrm{SW}}$ and $\left.\gamma_{2}(t) \cdot T_{\mathrm{SW}}\right)$. The result is that $\left|\mathrm{v}_{\mathrm{T}}(\mathrm{f})\right|$ differs from delta functions centered at the switching harmonics and depends on the modulation scheme. Fig. 13(a) shows the estimated spectrum magnitude (in blue) by using MATLAB when considering a 64QAM scheme and $\mathrm{T}_{\mathrm{SYM}}$ equal to $3 \cdot \mathrm{T}_{\mathrm{SW}}$. This means that a single

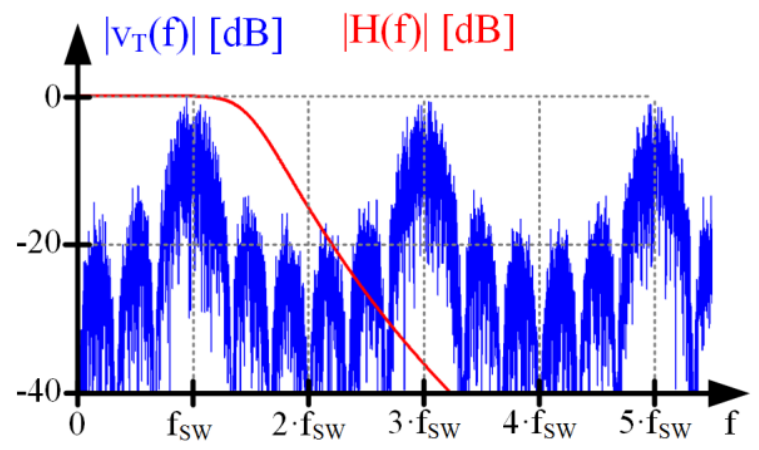

(a)

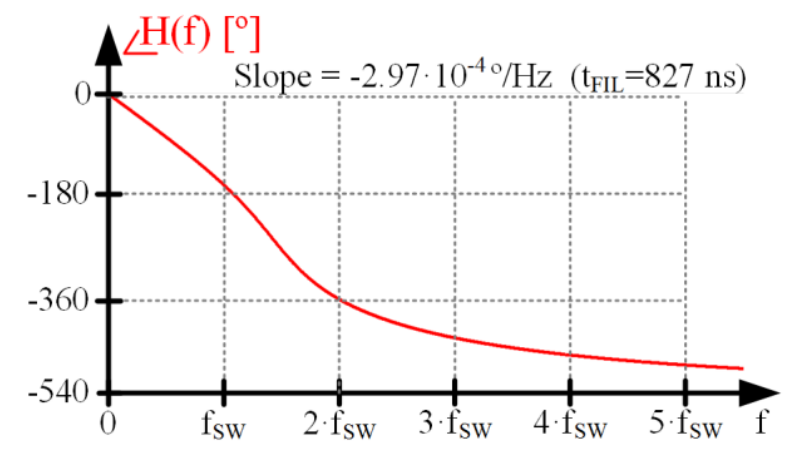

(b)

Fig. 13. Estimated $\mathrm{v}_{\mathrm{T}}(\mathrm{t})$ spectrum magnitude and low-pass filter design. Note that the DC component of $\mathrm{v}_{\mathrm{T}}(\mathrm{f})$ is removed and the result is normalized to the maximum value. 
symbol is represented by three carrier periods, which in this case is equal to three switching periods. Since the DC component is a delta function at $0 \mathrm{~Hz}$ that does not jeopardize the filter design, the DC component is removed from Fig. 13(a) and the result is normalized to the maximum value. Fig. 13 also shows the magnitude [see Fig. 13(a)] and phase response [see Fig. 13(b)] of the filter in red.

In order to avoid distortion, the magnitude of the filter transfer function must be constant and its phase-shift must be linear with frequency (this means a constant group delay) for all the desired frequency components [59]-[62]. In addition, it must ensure enough rejection of the undesired frequency components. At this point, the use of a high order filter is suitable [72]. It is important to note that considering the proposed structure for the DC-DC power converter, even harmonics are null when the duty cycle is 0.5 . This fact facilitates the filtering task and, as Fig. 13(a) shows, this potential benefit is used in the example. In any case, the method is also valid without making use of this option. The filter design of the example is a sixth-order Butterworth filter with $\mathrm{f}_{\mathrm{C}}$ equal $1.5 \cdot f_{\mathrm{SW}}$. The delay introduced by the filter (i.e., $\mathrm{t}_{\mathrm{FIL}}$ ) can be estimated from the slope of the filter phase response for the

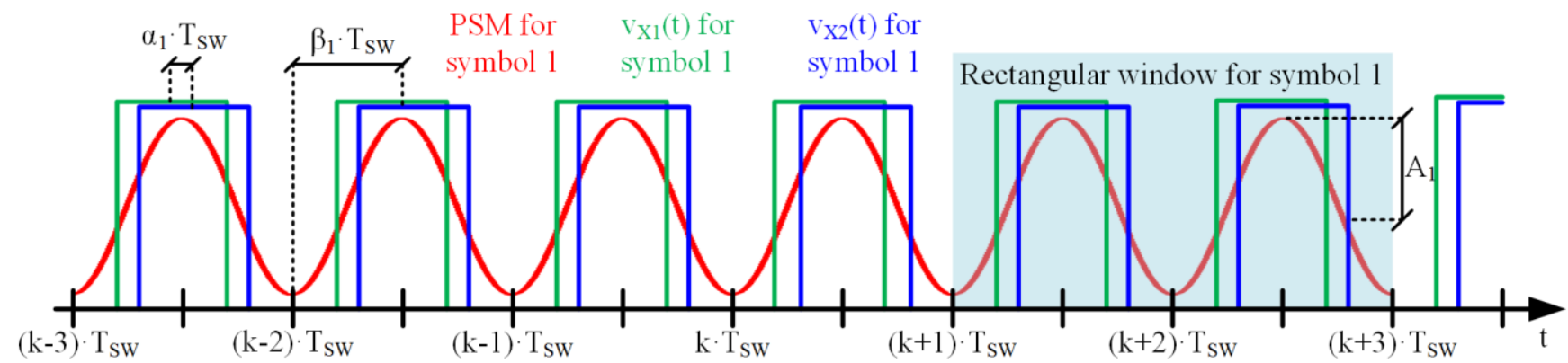

(a)

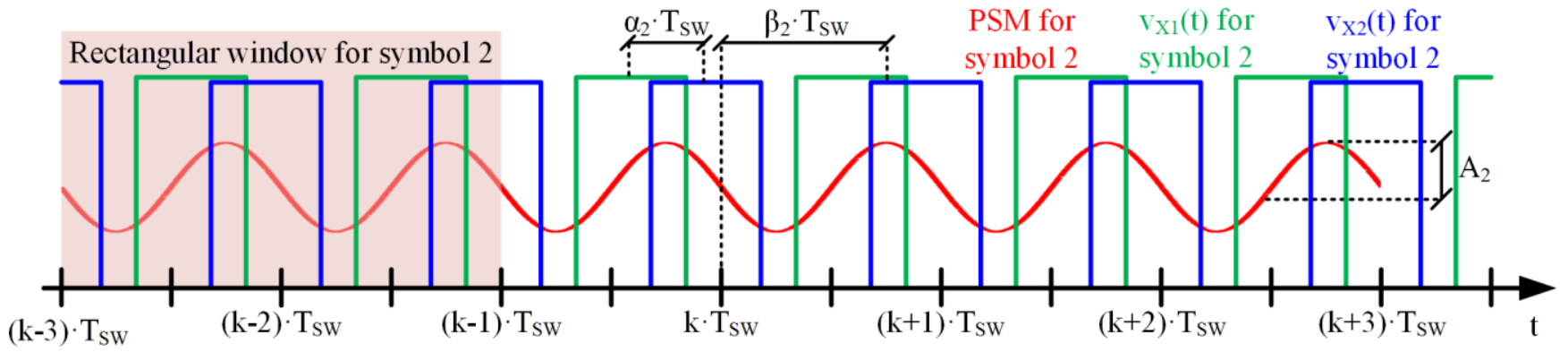

(b)

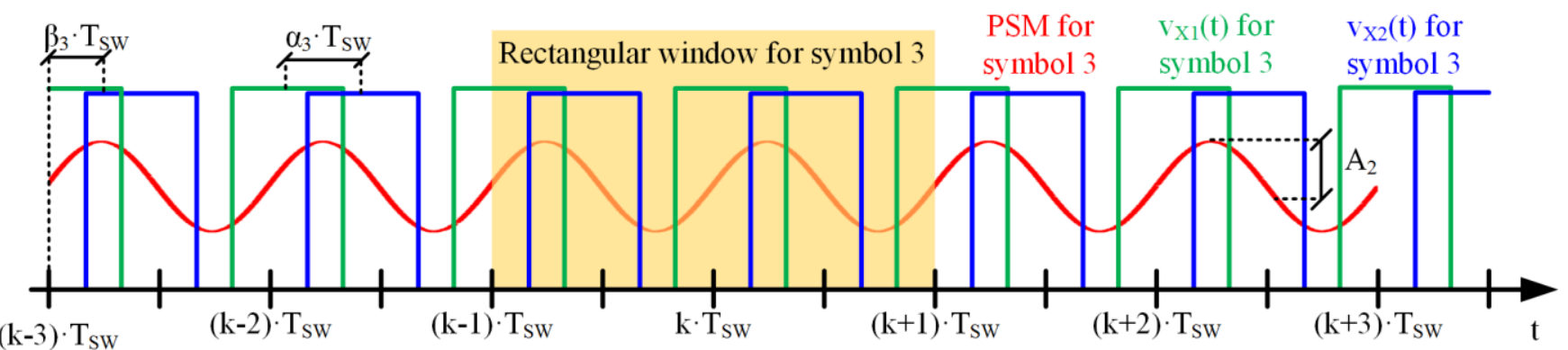

(c)

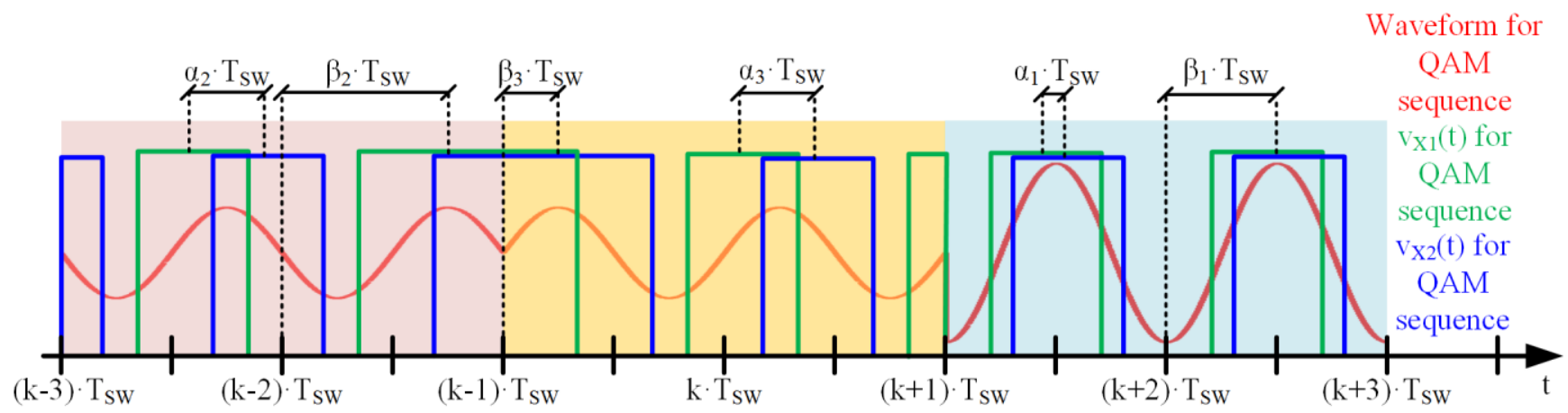

(d)

Fig. 14. Construction of the QAM sequence by applying the rectangular windows to three different Pure Sinusoidal Waveforms (PSMs): (a) PSM for symbol 1 with its rectangular window. (b) PSM for symbol 2 with its rectangular window. (c) PSM for symbol 3 with its rectangular window. (d) Resultant sequence. 
desired frequency components. The value for this example is around $827 \mathrm{~ns}$.

\section{QAM Sequence Generation}

In this section, a qualitative explanation of a QAM sequence implementation is expounded. Instantaneous changes in values of $\alpha$ and $\beta$ must be considered and, as a consequence, the resultant sinusoidal waveform can show abrupt changes in its amplitude and phase when a transient between symbols occurs. Hence, this waveform can be seen as a concatenation of different Pure Sinusoidal Waveforms (PSMs) portions (i.e., sinusoidal waveforms whose amplitude, phase and frequency is constant over time). Obviously, each PSM portion represents a specific symbol. From a theoretical point of view, this fact is equivalent to have NS different PSMs available that have a certain amplitude and phase according to the symbol that each one represents, and some parts of them are extracted in order to build the desired waveform. Fig. 14 shows an example in which three different symbols are considered. The amplitude and the phase of the symbol 1 are $A_{1}$ and $-180^{\circ}$, respectively [Fig. 14(a)]. The amplitude of symbols 2 and 3 are $A_{2}$, and their phases are $-270^{\circ}$ [Fig. 14(b)] and $-90^{\circ}$ [Fig. 14(c)], respectively. $\mathrm{T}_{\mathrm{SYM}}$ is equal to $2 \cdot \mathrm{T}_{\mathrm{SW}}$ and the desired sequence is symbol 2 , symbol 3 and symbol 1 . In the signal processing field it is equivalent to apply a rectangular window to a sinusoidal waveform of infinite time duration. This is the operation that causes the spectral broadening of each harmonic that conditions the output filter design [see Fig. 13(a) into Section V.C)].

\section{EXPERIMENTAL RESULTS AND IMPROVEMENT EVALUATION}

\section{A. Prototype Details}

A two-phase synchronous buck converter with sixth-order Butterworth filter supplying 6 HB-LEDs (W42180 Seoul Semiconductor) connected in series as load was built (see Fig. 15). The switching frequency is $500 \mathrm{kHz}$ and the maximum power is around $10 \mathrm{~W}$. MOSFETs CSD88539ND are used driven by LM5101AMX/NOPB ICs. The control signals are generated by a FPGA. The low-pass filter corresponds to the design detailed in Section V.C: sixth-order Butterworth filter with $\mathrm{f}_{\mathrm{C}}$ equal to $1.5 \cdot \mathrm{f}_{\mathrm{Sw}}\left(\right.$ i.e., $\mathrm{f}_{\mathrm{C}}=750 \mathrm{kHz}$ ). Table I shows the ideal values of the passive components. The delay introduced by the filter is $672 \mathrm{~ns}$. The difference with respect to the value calculated in Section V.C (i.e., 827 ns) is due to the tolerance of the passive components. A precision resistor $\left(\mathrm{R}_{\mathrm{SEN}}\right)$ of 0.25 $\Omega$ is connected in series with the HB-LEDs in order to measure the output current by measuring its voltage ( $\mathrm{v}_{\text {SEN }}$ ). A biasing output voltage of $18.9 \mathrm{~V}$ is stablished to impose an average current of $440 \mathrm{~mA}$ flowing through the HB-LEDs at the operating condition. The duty cycle is 0.5 to cancel the even harmonics of $\mathrm{v}_{\mathrm{T}}(\mathrm{t})$ in order to make less restrictive the output filter design. To achieve all these specifications, the input voltage is defined as $37.8 \mathrm{~V}$.

\section{B. QAM Scheme Demonstration}

In order to proof the concept, an example of 64-QAM scheme is implemented by using the prototype presented in Section
VI.A. 8 different amplitudes and 8 different phases are stablished. Table II shows the different current amplitudes (i $\left.\mathrm{i}_{\mathrm{AMP}}\right)$ and phases with the bit code that identifies each one. There are 64 possible symbols and, as a consequence, each symbol transmits 6 bits. The codification example is defined as follows: the 3 bits that identify a certain amplitude are interpreted as the 3 most significant bits of the symbol and the 3 bits that identify a certain phase are interpreted as the 3 least significant bits of the symbol. Fig. 16 shows the constellation diagram (dots in red) of the reproduced 64-QAM scheme.

It is important to note that $\mathrm{T}_{\mathrm{SYM}}$ is equal to $3 \cdot \mathrm{T}_{\mathrm{SW}}$ (i.e., 3 periods of the carrier). The bit rate achieved is $1 \mathrm{Mbps}$ and the efficiency of the DC-DC power converter is around $86 \%$.

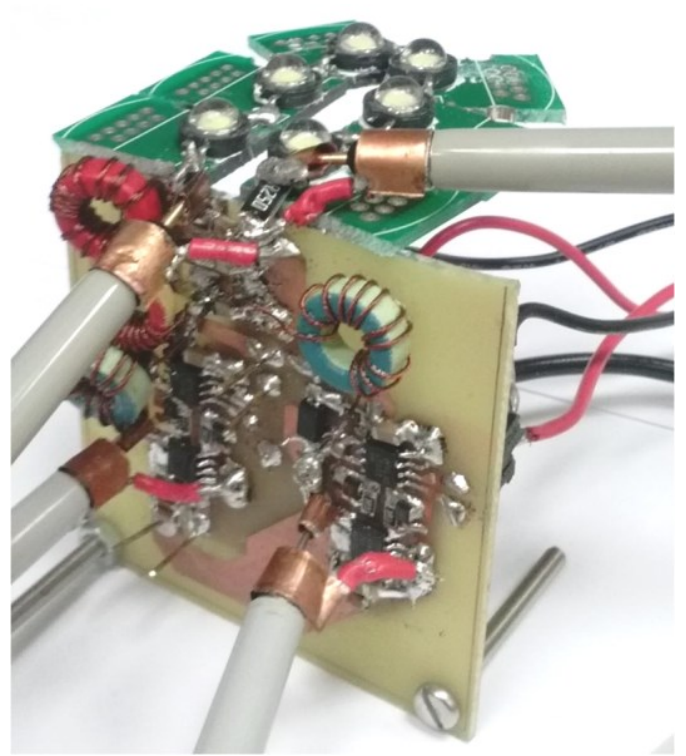

Fig. 15. Two-phase synchronous buck converter prototype with sixth-order Butterworth filter supplying 6 HB-LEDs connected in series as load.

TABLE I. THEORETICAL VALUES OF THE $6^{\text {TH }}$-ORDER Butterworth FiLter.

\begin{tabular}{|c|c|c|c|c|c|c|c|}
\hline Component & $\begin{array}{c}\mathrm{L}_{1 \mathrm{~A}} \\
(\mu \mathrm{H})\end{array}$ & $\begin{array}{c}\mathrm{L}_{1 \mathrm{~B}} \\
(\mu \mathrm{H})\end{array}$ & $\begin{array}{c}\mathrm{C}_{2} \\
(\mathrm{nF})\end{array}$ & $\begin{array}{c}\mathrm{L}_{3} \\
(\mu \mathrm{H})\end{array}$ & $\begin{array}{c}\mathrm{C}_{4} \\
(\mathrm{nF})\end{array}$ & $\begin{array}{c}\mathrm{L}_{5} \\
(\mu \mathrm{H})\end{array}$ & $\begin{array}{c}\mathrm{C}_{6} \\
(\mathrm{nF})\end{array}$ \\
\hline Value & 4.39 & 4.39 & 56 & 2.2 & 38.25 & 1.07 & 8.24 \\
\hline
\end{tabular}

TABLE II. AMPLITUdES AND PHASES DeFINITION FOR THE 64-QAM SCHEME.

\begin{tabular}{|c|c|c|c|c|c|}
\hline \multicolumn{3}{|c|}{ Amplitudes } & \multicolumn{3}{c|}{ Phases } \\
\hline ID & $\mathbf{i}_{\text {AMP }}(\mathbf{m A})$ & Bit code & ID & Phase ( $\left.{ }^{\circ}\right)$ & Bit code \\
\hline $\mathrm{A}_{1}$ & 104.57 & 000 & $\mathrm{P}_{1}$ & 0 & 000 \\
\hline $\mathrm{A}_{2}$ & 159.86 & 001 & $\mathrm{P}_{2}$ & -45 & 001 \\
\hline $\mathrm{A}_{3}$ & 203.13 & 010 & $\mathrm{P}_{3}$ & -90 & 010 \\
\hline $\mathrm{A}_{4}$ & 254.81 & 011 & $\mathrm{P}_{4}$ & -135 & 011 \\
\hline $\mathrm{A}_{5}$ & 296.88 & 100 & $\mathrm{P}_{5}$ & -180 & 100 \\
\hline $\mathrm{A}_{6}$ & 349.76 & 101 & $\mathrm{P}_{6}$ & -225 & 101 \\
\hline $\mathrm{A}_{7}$ & 405.05 & 110 & $\mathrm{P}_{7}$ & -270 & 110 \\
\hline $\mathrm{A}_{8}$ & 440 & 111 & $\mathrm{P}_{8}$ & -315 & 111 \\
\hline
\end{tabular}


Fig. 17 shows a part of a 64-QAM sequence in which four symbols can be identified. Note that $\left\langle_{\mathrm{VEN}}(\mathrm{t})\right\rangle$ is the average value of $v_{\operatorname{SEN}}(t)$ and it is related to the average current that flows through the HB-LEDs. The received symbols of this example are included in Fig. 16 (dots in blue). Fig. 18 shows the fast transition achieved when a change in the amplitude is performed. It can be seen that the transition instant at the output (i.e., $v_{O}(t)$ and $\left.v_{S E N}(t)\right)$ is delayed t tFL with respect to the transition instant at the input of the filter (i.e., $v_{\mathrm{X} 1}(\mathrm{t})$ and $\mathrm{v}_{\mathrm{X} 2}(\mathrm{t})$ ). Regarding the accuracy achieved, it can be seen that the maximum error appear during the transition. This is the part where the highest difference between the experimental (yellow

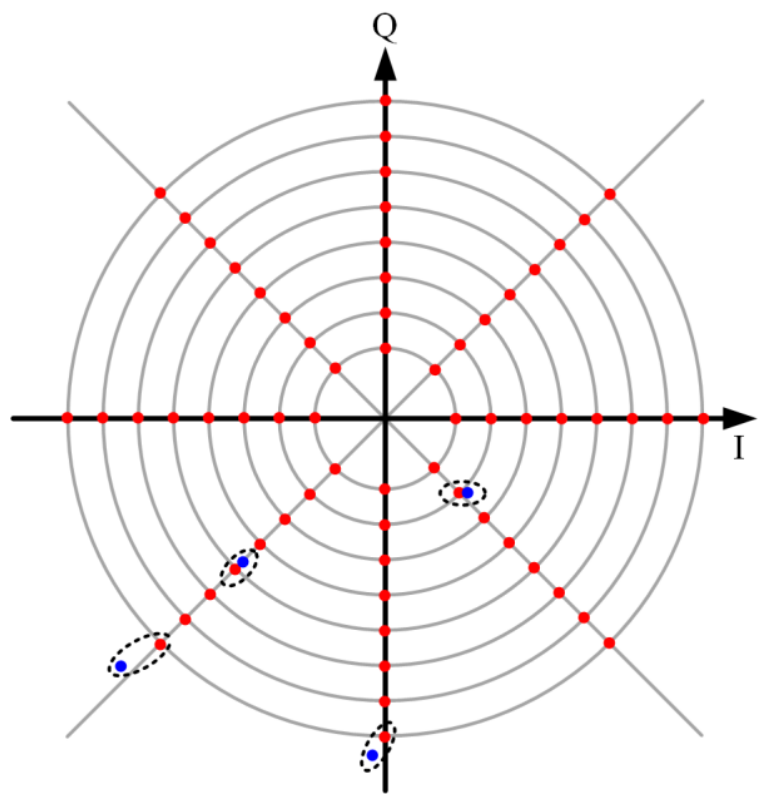

Fig. 16. Constellation diagram of the reproduced 64-QAM scheme (dots in red). The received symbols of the example shown in Fig. 17 are also included (dots in blue).

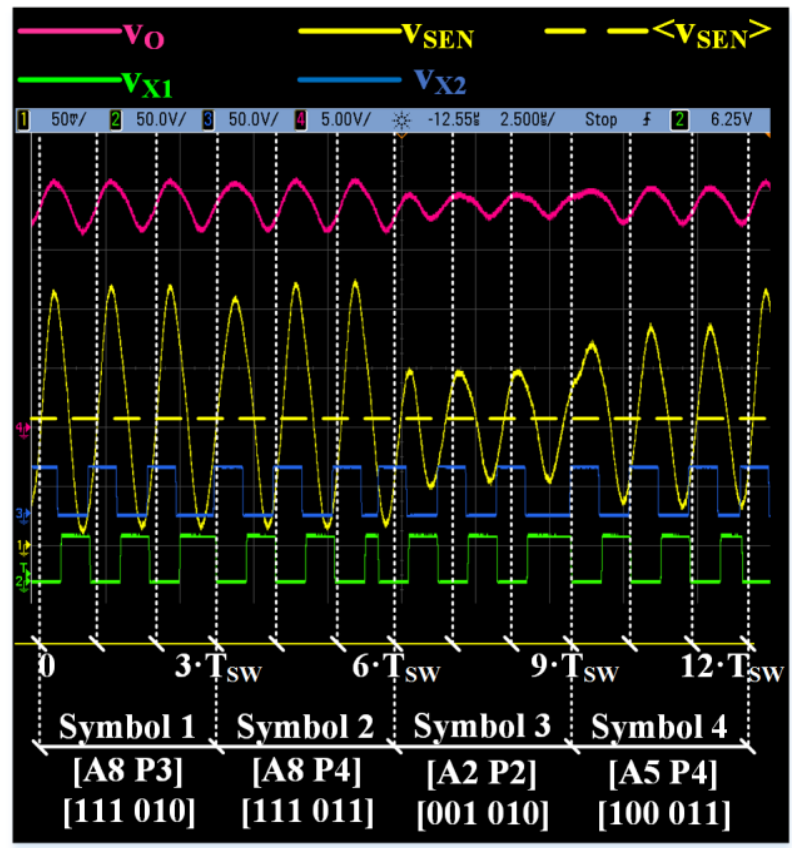

Fig. 17. Portion of the experimental 64-QAM sequence where four symbols are highlighted. solid line) and the theoretical (yellow dashed line) appears. Fig. 19 shows a part of a sequence where all the possible amplitudes are generated. Note that in this example each symbol is transmitted twice (the amplitude keeps constant over $6 \cdot \mathrm{T}_{\mathrm{SW}}$ ). Fig. 20 shows the results obtained when a phase transition is performed. The phase step is equal to $-90^{\circ}$. As in the previous case, the maximum error appears during the transition.

Finally, the VLC system is evaluated by receiving the transmitted signal using the setup shown in Fig. 21. The commercial available receiver PDA10A-EC is utilized during the tests. The distance between the VLC transmitter prototype and the receiver is around $60 \mathrm{~cm}$. Fig. 22 shows the main waveforms involved in the test when a sequence is transmitted and received. Note that $\mathrm{v}_{\mathrm{RX}}(\mathrm{t})$ is the signal at the receiver.

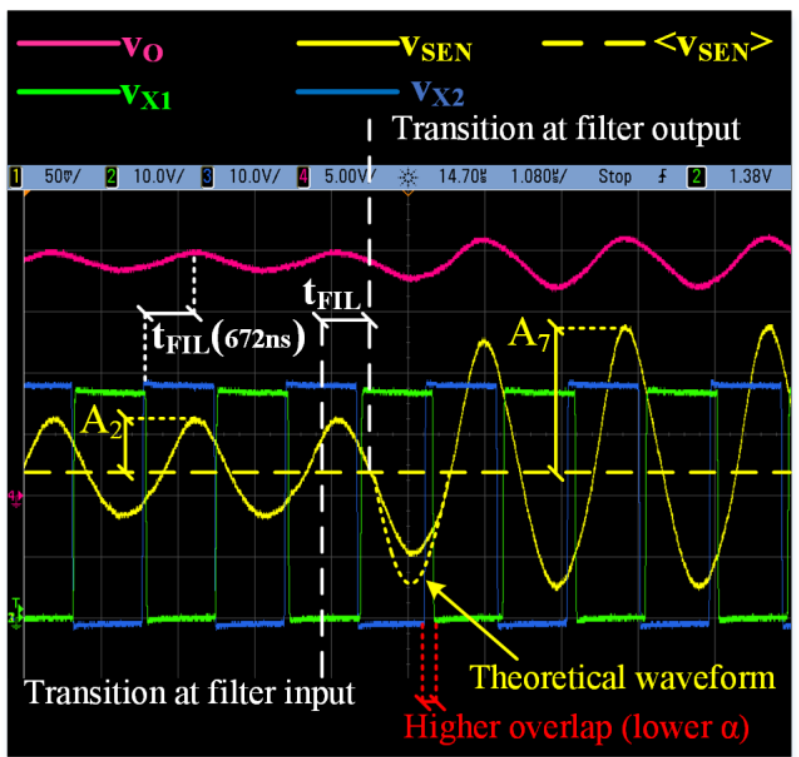

Fig. 18. Detail of a transition when a change in the amplitude is performed. Instants in which the transition occurs at the output and at the input of the filter are highlighted.

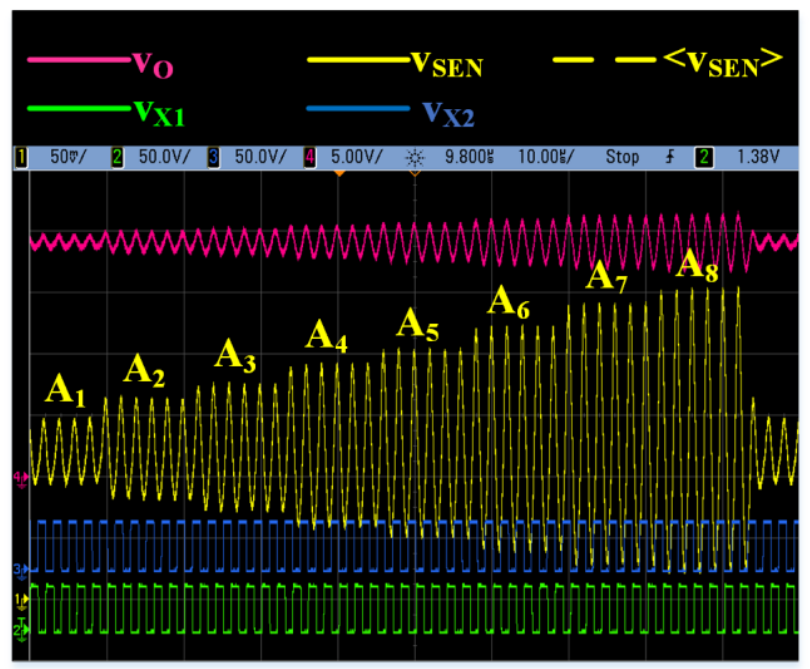

Fig. 19. Sequence where all the possible amplitudes are generated. Note that in this case, the amplitude keeps constant over $6 \cdot \mathrm{T}_{\mathrm{SW}}$. 


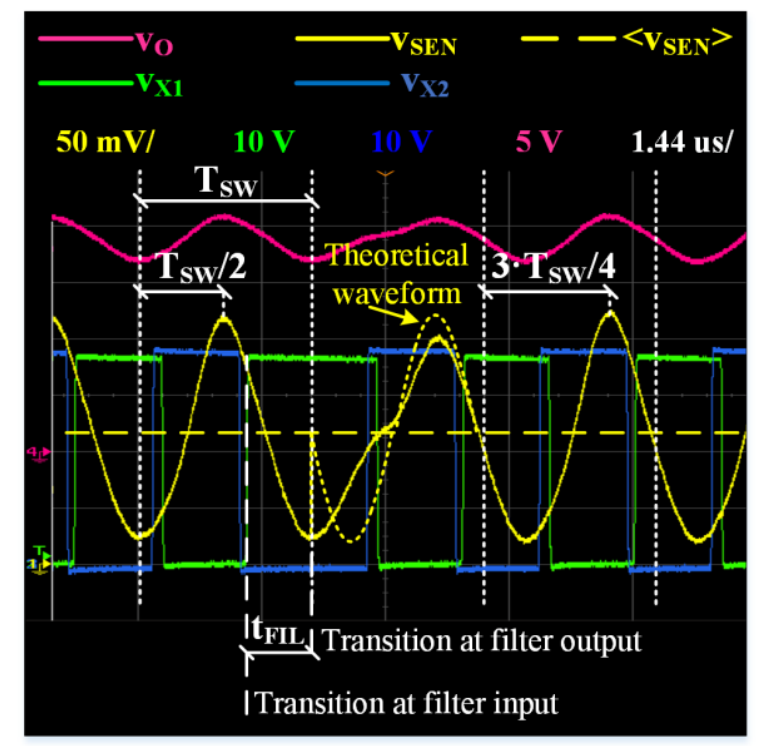

Fig. 20. Detail of a transition when a change in the phase is performed. The phase step is equal to $-90^{\circ}$. Instants in which the transition occurs at the output and at the input of the filter are highlighted.

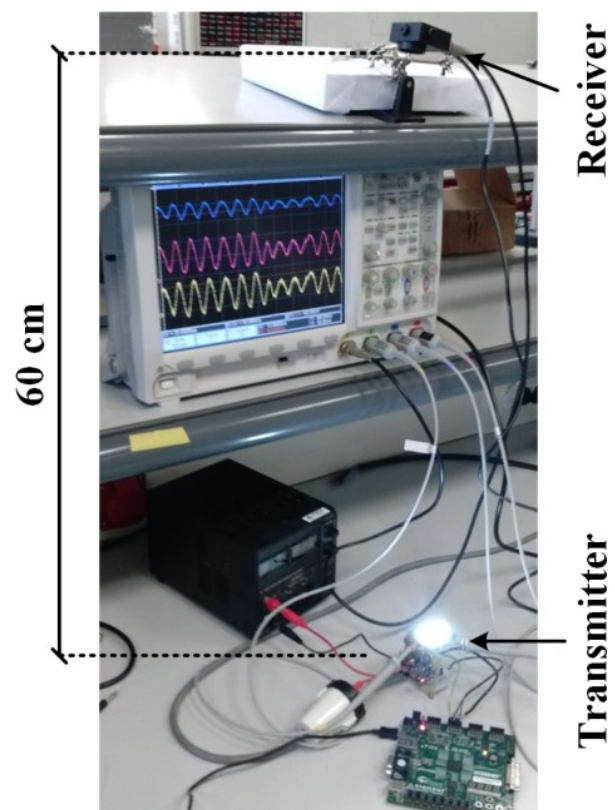

Fig. 21. VLC system setup.

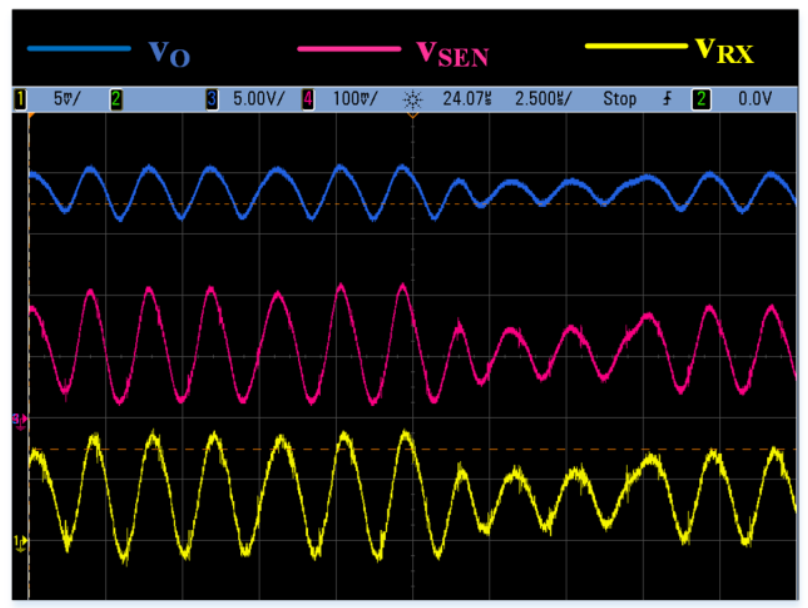

Fig. 22. Main waveforms involved in the test of the VLC system.

\section{Transmission Evaluation}

In order to test the communication system, the received signal is demodulated with Matlab. At this point, the definition of the in-phase and quadrature components is mandatory. Along the paper, the symbols were described according to the polar coordinates (i.e., a combination of a certain amplitude with a certain phase):

$$
\bar{V}=A e^{j \phi} .
$$

However, the traditional architecture of the QAM demodulator (see Fig. 23) is based on the Cartesian coordinates:

$$
\bar{V}=A \cos (\phi)+j A \sin (\phi) .
$$

Thus, the in-phase component (i.e., horizontal component in Fig. 16) is:

$$
V_{I}=A \cos (\phi) .
$$

Similarly, the quadrature component (i.e., vertical component in Fig. 16) is:

$$
V_{Q}=A \sin (\phi) .
$$

The expression of the voltage at the output of the transimpedance amplifier is:

$$
\begin{aligned}
& v_{R X}(t)=v_{R X-D C}+ \\
& A_{R X}(t) \cos \left(2 \pi f_{S W} t+\phi_{R X}(t)\right)+v_{R X-D C},
\end{aligned}
$$

where $A_{R X}(t)$ is the received amplitude, $\phi_{R X}(t)$ is the received phase and $\mathrm{V}_{\mathrm{RX}-\mathrm{DC}}$ is the DC component. The first step is to remove the lighting component (i.e., $\mathrm{V}_{\mathrm{RX}-\mathrm{DC}}$ ) with a high-pass filter. Thus, $\mathrm{v}_{\mathrm{RX}-\mathrm{AC}}(\mathrm{t})$ is obtained:

$$
v_{R X-A C}(t)=A_{R X}(t) \cos \left(2 \pi f_{S W} t+\phi_{R X}(t)\right) .
$$

Then, this signal is processed through two different paths. In the upper one, $\mathrm{V}_{\mathrm{RX}-\mathrm{AC}}(\mathrm{t})$ is multiplied by the local oscillator, whose frequency is equal to $f_{S w}$ :

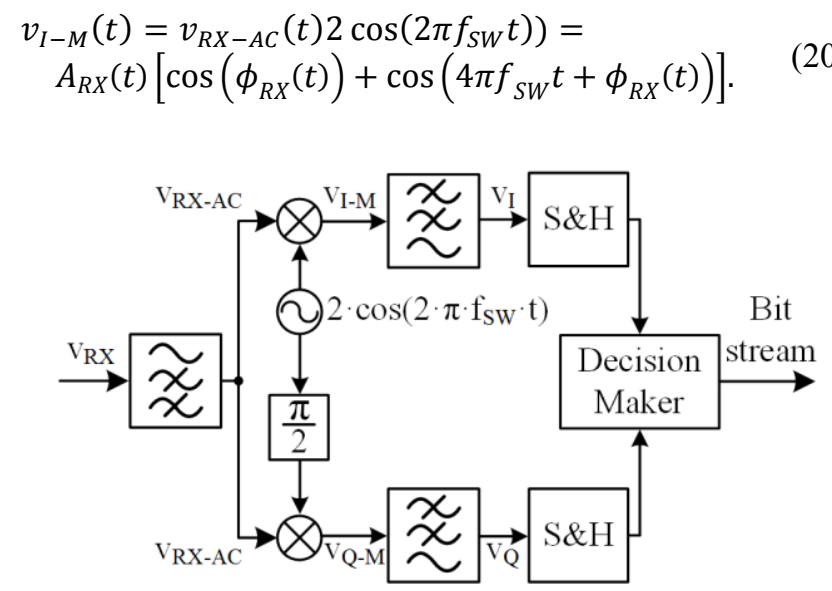

Fig. 23. Diagram of the QAM demodulator implemented in Matlab. 
After that, the frequency component at $2 \cdot \mathrm{f}_{\mathrm{Sw}}$ is removed with a low-pass filter, obtaining the in-phase component of the received signal:

$$
v_{I}(t)=A_{R X}(t) \cos \left(\phi_{R X}(t)\right)
$$

In the lower path, $\mathrm{v}_{\mathrm{RX}-\mathrm{AC}}(\mathrm{t})$ is multiplied by the local oscillator with a phase-shift of $90^{\circ}$ :

$$
\begin{aligned}
& v_{Q-M}(t)=v_{R X-A C}(t) 2 \cos \left(2 \pi f_{S W} t+\frac{\pi}{2}\right)= \\
& A_{R X}(t)\left[\sin \left(\phi_{R X}(t)\right)-\sin \left(4 \pi f_{S W} t+\phi_{R X}(t)\right)\right] .
\end{aligned}
$$

After that, the frequency component at $2 \cdot \mathrm{f}_{\mathrm{SW}}$ is removed with a low-pass filter, obtaining the quadrature component of the received signal:

$$
v_{Q}(t)=A_{R X}(t) \sin \left(\phi_{R X}(t)\right)
$$

Both $\mathrm{v}_{\mathrm{I}}(\mathrm{t})$ and $\mathrm{v}_{\mathrm{Q}}(\mathrm{t})$ are sampled and sent to the decision maker block, which estimates that the received symbol is the closest one considering the constellation diagram depicted in Fig. 16. Fig. 24 exemplifies the demodulation process using the sequence portion shown in Fig. 17.

Finally, to measure the accuracy of the communications system, the error vector $(\overline{\mathrm{e}})$ is employed:

$$
\bar{e}=\bar{W}-\bar{V},
$$

where $\overline{\mathrm{W}}$ is the received symbol and $\overline{\mathrm{V}}$ is the ideal symbol (see Fig. 25).

The root mean square value of the Error Vector Magnitude $\left(E M_{R M S}\right)$ is a widely used figure-of-merit that evaluates the performance of the communication system. $E_{\text {VMMS }}$ is based on calculating $\overline{\mathrm{e}}$ for a sequence of $\mathrm{N}$ symbols, considering the average power of the involved symbols:

$$
E V M_{R M S}=\sqrt{\frac{\sum_{k=1}^{N}\left|\overline{e_{k}}\right|^{2}}{\sum_{k=1}^{N}\left|\overline{V_{k}}\right|^{2}}}
$$

The measured $\mathrm{EVM}_{\mathrm{RMS}}$ of the implemented communication system is $14.6 \%$ when considering the sequence of four symbols (i.e., 24 bits) depicted in Fig. 24. Typically, EVM RMS is evaluated for longer sequences and a value around 5\%-15\% is usually required to fulfill the requirements of wireless communication systems [62].

\section{Bit Rate/f $f_{S W}$ Evaluation}

As it is explained in the Section II.E, the target of this research is to improve the results achieved in [37] and [39] (i.e., power efficient approach reproducing an inefficient modulation scheme), alleviating the trade-off between communication and power efficiency. Due to the high $\mathrm{f}_{\mathrm{Sw}}$ required, the power losses of the HB-LED drivers for VLC are dominated by the switching losses. Therefore, the bit rate achieved by the VLC transmitter divided by the required $\mathrm{fSW}_{\mathrm{SW}}$ of the DC-DC power converter is a

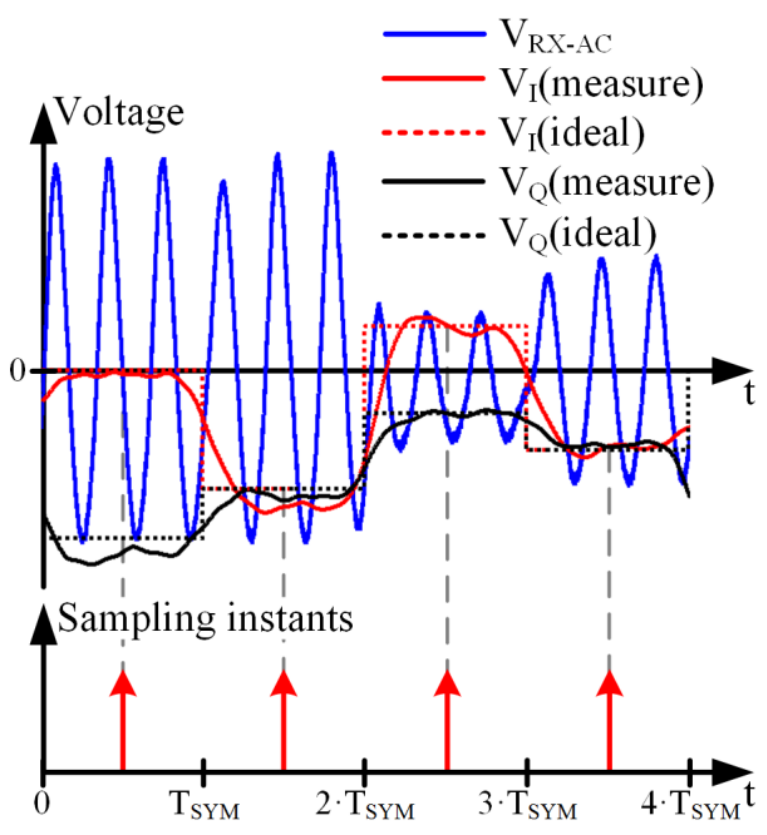

Fig. 24. Demodulation process example.

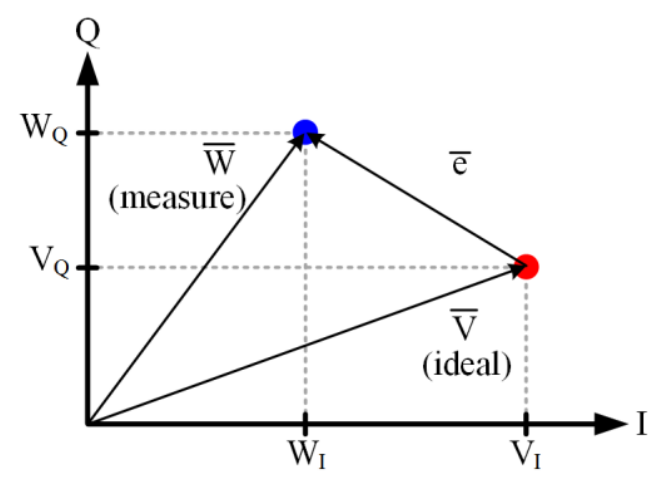

Fig. 25. Graphical interpretation of the error vector.

suitable figure-of-merit to evaluate each solution.

In [37], the reproduced VPPM scheme is limited by the current control loop. As a consequence, the bit rate achieved is ten times lower than $\mathrm{f}_{\mathrm{Sw}}$ : $50 \mathrm{kbps}$ is achieved using $\mathrm{f}_{\mathrm{SW}}$ equal to $500 \mathrm{kHz}$. The method proposed in [39] also reproduces a VPPM scheme, but reduces the current control loop limitation. In this case, the bit rate achieved is equal to $\mathrm{f}_{\mathrm{Sw}}$ : $2 \mathrm{Mbps}$ is achieved using $\mathrm{f}_{\mathrm{SW}}$ equal to $2 \mathrm{MHz}$. Since the bit rate achieved by the method proposed in this work depends on the specific singlecarrier digital modulation scheme that is reproduced, equation (26) must be considered to evaluate the figure-of-merit:

$$
\frac{\text { bit rate }}{f_{S W}}=\frac{T_{S W} \log _{2}(N S)}{T_{S Y M}} .
$$

Note that the bit rate rises with NS. Moreover, the lower the symbol period (i.e., $\mathrm{T}_{\mathrm{SYM}}$ ), the higher the bit rate. In the case of the developed prototype, the bit rate achieved is $1 \mathrm{Mbps}$ because a 64-QAM scheme is reproduced and $\mathrm{T}_{\mathrm{SYM}}$ is equal to $6 \mu$ s (i.e., $3 \cdot \mathrm{T}_{\mathrm{SW}}$ ).

Fig. 26 shows the figure-of-merit evaluation for each method. Method A and B denote the approaches for 


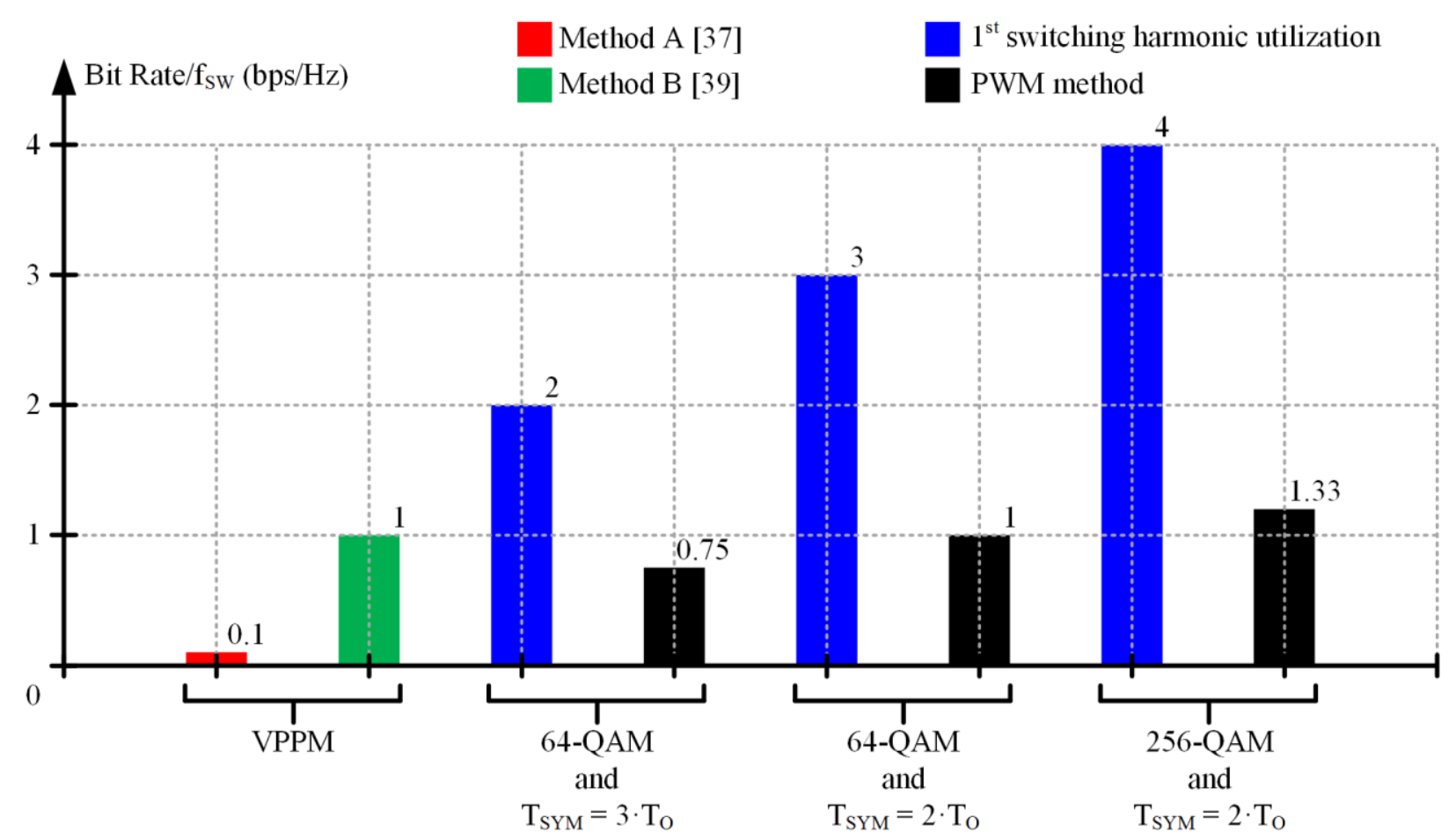

Fig. 26. Bit rate/ $\mathrm{f}_{\mathrm{SW}}$ evaluation for different approaches of VLC transmitters based on the use of DC-DC power converters.

reproducing VPPM schemes that are presented in [37] and [39], respectively. Blue columns represent the results provided by the method presented in this work for reproducing single-carrier digital modulation schemes by controlling the first switching harmonic of the DC-DC power converter output voltage ripple. Black columns correspond to the method able to reproduce this kind of modulation schemes by using the PWM technique (i.e., the method detailed in Section IV.A) and considering $f_{\mathrm{Sw}}=2 \cdot \mathrm{f}_{\mathrm{S}}$ MAX. These two last methods are evaluated for three different modulation schemes. It is important to note that in the case of the PWM method, when $\mathrm{T}_{\mathrm{SYM}}$ is reduced to increase the bit rate, the bandwidth of the signal to be reproduced is higher and, as a result, the required $\mathrm{f}_{\mathrm{SW}}$ rises. However, in the case of the method proposed in this paper, $\mathrm{fSW}_{\mathrm{SW}}$ is independent of $\mathrm{T}_{\mathrm{SYM}}$.

In summary, the highest ratio between bit rate and $f_{\mathrm{SW}}$ is achieved by the method presented in this work. This is due to the high spectral efficiency provided by the single-carrier digital modulation schemes and due to the fact that by using the proposed method, the required $f_{S W}$ is equal to $f_{O}$.

\section{CONCLUSIONS}

VLC is an application with great potential for the future that has achieved extremely high bit rates during last years. However, the HB-LED drivers proposed for achieving such speeds offer low power efficiency. Consequently, there is a trade-off between communication and power efficiency that this research has aimed to alleviate. The proposed two-phase synchronous buck converter for VLC transmitters is able to reproduce single-carrier digital modulation schemes and to fulfill the lighting functionality. The DC-DC power converter takes advantage of the output voltage ripple using a method that is not reported in literature: controlling the amplitude and the phase of the output voltage ripple first switching harmonic by modifying the phase of the switch-node voltage of each phase of the converter. Most relevant theoretical base of the method is explained and a $10 \mathrm{~W}$ prototype that implements a $64-\mathrm{QAM}$ is presented.

In comparison to the previously proposed DC-DC power converters for VLC transmitters, the presented approach achieves the highest ratio between bit rate and switching frequency. Moreover, improving the result by reducing $\mathrm{T}_{\mathrm{SYM}}$ or using a more complex QAM-scheme seems to be an achievable goal.

Another important point is that the techniques for enhancing the available bandwidth are compatible with the proposed method, thus showing the possibility of attaining higher data rates in the future.

\section{ACKNOWLEDGMENT}

This work has been supported by the Spanish Government under the Project MINECO-17-DPI2016-75760-R, the scholarship FPU14/03268 and the Principality of Asturias under the Project FC-15- GRUPIN14-143 and by European Regional Development Fund (ERDF) grants.

\section{REFERENCES}

[1] Cisco Systems, "Cisco visual networking index: global mobile data traffic forecast update, 2016-2021", Feb. 2017. [Online]. Available: http://www.cisco.com/c/en/us/solutions/collateral/serviceprovider/visual-networking-index-vni/mobile-white-paper-c11520862.html

[2] L. Atzori, A. Iera, and G. Morabito, "The internet of things: a survey," Comput. Netw., vol. 54, no. 15, pp. 2787-2805, 2010.

[3] J. Gubbi, R. Buyya, S. Marusic, and M. Palaniswami, "Internet of Things 
(IoT): a vision, architectural elements, and future directions," Future Generat. Comput. Syst., vol. 29, no. 7, pp. 1645-1660, Sep. 2013. [Online]. Available: http://dx.doi.org/10.1016/j.future.2013.01.010

[4] "IEEE standard for local and metropolitan area networks--part 15.7: short-range wireless optical communication using visible light," in IEEE Std 802.15.7-2011, vol., no., pp.1-309, Sept. 62011.

[5] GBI Research, "Visible Light Communication (VLC)—a potential solution to the global wireless spectrum shortage", Sep. 2011 [Online]. Available: http://www.gbiresearch.com

[6] H. Elgala, R. Mesleh, and H. Haas, "Indoor optical wireless communication: potential and state-of-the-art," IEEE Commun. Mag., vol. 49, no. 9, pp. 56-62, Sep. 2011.

[7] A. Jovicic, J. Li and T. Richardson, "Visible light communication: opportunities, challenges and the path to market," in IEEE Communications Magazine, vol. 51, no. 12, pp. 26-32, December 2013.

[8] T. Komine and M. Nakagawa, "Fundamental analysis for visible-light communication system using LED lights," in IEEE Transactions on Consumer Electronics, vol. 50, no. 1, pp. 100-107, Feb 2004.

[9] A. Sevincer, A. Bhattarai, M. Bilgi, M. Yuksel and N. Pala, "Lightnets: smart lighting and mobile optical wireless networks - a survey," in IEEE Communications Surveys \& Tutorials, vol. 15, no. 4, pp. 16201641, Fourth Quarter 2013.

[10] A. Tsiatmas, C. P. M. J. Baggen, F. M. J. Willems, J. P. M. G. Linnartz and J. W. M. Bergmans, "An illumination perspective on visible light communications," in IEEE Communications Magazine, vol. 52, no. 7, pp. 64-71, July 2014.

[11] D. Karunatilaka, F. Zafar, V. Kalavally and R. Parthiban, "LED based indoor visible light communications: state of the art," in IEEE Communications Surveys \& Tutorials, vol. 17, no. 3, pp. 1649-1678, thirdquarter 2015.

[12] P. H. Pathak, X. Feng, P. Hu and P. Mohapatra, "Visible light communication, networking, and sensing: a survey, potential and challenges," in IEEE Communications Surveys \& Tutorials, vol. 17, no. 4, pp. 2047-2077, Fourthquarter 2015.

[13] H. Haas, C. Chen, D. O'Brien, "A guide to wireless networking by light", Progress in Quantum Electronics, 2017, ISSN 0079-6727, http://dx.doi.org/10.1016/j.pquantelec.2017.06.003.

[14] J. M. Kahn and J. R. Barry, "Wireless infrared communications," in Proceedings of the IEEE, vol. 85, no. 2, pp. 265-298, Feb 1997.

[15] J. A. J. Roufs and F. J. J. Blommaizt, "Temporal impulse and step responses of the human eye obtained psychophysically by means of a drift-correction perturbation technique", Vision Research, vol. 21, no. 8, pp. 1203-21, 1981.

[16] A. Wilkins, J. Veitch and B. Lehman, "LED lighting flicker and potential health concerns: IEEE standard PAR1789 update," 2010 IEEE Energy Conversion Congress and Exposition, Atlanta, GA, 2010, pp. 171-178.

[17] J. Grubor, S. C. J. Lee, K. D. Langer, T. Koonen and J. W. Walewski, "Wireless high-speed data transmission with phosphorescent white-light LEDs," 33rd European Conference and Exhibition of Optical Communication - Post-Deadline Papers (published 2008), Berlin, Germany, 2007, pp. 1-2.

[18] H. Le Minh et al., "100-Mb/s NRZ visible light communications using a postequalized white LED," in IEEE Photonics Technology Letters, vol. 21, no. 15, pp. 1063-1065, Aug.1, 2009.

[19] H. Li, X. Chen, B. Huang, D. Tang and H. Chen, "High bandwidth visible light communications based on a post-equalization circuit," in IEEE Photonics Technology Letters, vol. 26, no. 2, pp. 119-122, Jan.15, 2014.

[20] S. K. Liaw, H. H. Chou, C. J. Wu, M. J. Chien and C. Teng, "500 Mb/s OOK visible light communications using RGB-based LEDs," 2015 International Symposium on Next-Generation Electronics (ISNE), Taipei, 2015, pp. 1-2.

[21] J. Vučić, C. Kottke, K. Habel and K. D. Langer, "803 Mbit/s visible light WDM link based on DMT modulation of a single RGB LED luminary," Optical Fiber Communication Conference and Exposition (OFC/NFOEC), 2011 and the National Fiber Optic Engineers Conference, Los Angeles, CA, 2011, pp. 1-3.

[22] F. Wu, C. Lin, C. Wei, C. Chen, Z. Chen and H. Huang, "3.22-Gb/s WDM visible light communication of a single RGB LED employing carrier-less amplitude and phase modulation," 2013 Optical Fiber Communication Conference and Exposition and the National Fiber Optic Engineers Conference (OFC/NFOEC), Anaheim, CA, 2013, pp. 1-3.
[23] Y. Wang, X. Huang, J. Zhang, Y. Wang, N. Chi, "Enhanced performance of visible light communication employing 512QAM N-SC-FDE and DD-LMS", Opt. Exp., vol. 22, no. 13, pp. 15328-15334, Jun. 2014.

[24] Y. Wang, L. Tao, X. Huang, J. Shi and N. Chi, "8-Gb/s RGBY LEDbased WDM VLC system employing high-order CAP modulation and hybrid post equalizer," in IEEE Photonics Journal, vol. 7, no. 6, pp. 1-7, Dec. 2015

[25] H. Chun et al., "LED based wavelength division multiplexed $10 \mathrm{~Gb} / \mathrm{s}$ visible light communications," in Journal of Lightwave Technology, vol. 34, no. 13, pp. 3047-3052, July1, 12016.

[26] R. Singh, T. O'Farrell and J. P. R. David, "Performance evaluation of IEEE 802.15.7 CSK physical layer," 2013 IEEE Globecom Workshops (GC Wkshps), Atlanta, GA, 2013, pp. 1064-1069.

[27] E. Monteiro and S. Hranilovic, "Design and implementation of colorshift keying for visible light communications," in Journal of Lightwave Technology, vol. 32, no. 10, pp. 2053-2060, May15, 2014.

[28] R. Singh, T. O'Farrell and J. P. R. David, "An enhanced color shift keying modulation scheme for high-speed wireless visible light communications," in Journal of Lightwave Technology, vol. 32, no. 14, pp. 2582-2592, July15, 152014.

[29] R. X. G. Ferreira et al., "High bandwidth GaN-based micro-LEDs for multi-Gb/s visible light communications," in IEEE Photonics Technology Letters, vol. 28, no. 19, pp. 2023-2026, Oct.1, 12016.

[30] Y. F. Yin, W. Y. Lan, T. C. Lin, C. Wang, M. Feng and J. J. Huang, "High-speed visible light communication using GaN-based lightemitting diodes with photonic crystals," in Journal of Lightwave Technology, vol. 35, no. 2, pp. 258-264, Jan.15, 152017.

[31] M. S. Islim, R. X. Ferreira, X. He, E. Xie, S. Videv, S. Viola, S. Watson, N. Bamiedakis, R. V. Penty, I. H. White, and A. E. Kelly, "Towards 10 $\mathrm{Gb} / \mathrm{s}$ orthogonal frequency division multiplexing-based visible light communication using a GaN violet micro-LED," Photon. Res. 5(2), 3543 (2017)

[32] L. Zeng et al., "High data rate Multiple Input Multiple Output (MIMO) optical wireless communications using white LED lighting," in IEEE Journal on Selected Areas in Communications, vol. 27, no. 9, pp. 16541662, December 2009.

[33] A. H. Azhar, T. A. Tran and D. O'Brien, "A Gigabit/s indoor wireless transmission using MIMO-OFDM visible-light communications," in IEEE Photonics Technology Letters, vol. 25, no. 2, pp. 171-174, Jan.15, 2013.

[34] A. Burton, H. Le Minh, Z. Ghassemlooy, E. Bentley and C. Botella, "Experimental demonstration of $50-\mathrm{Mb} / \mathrm{s}$ visible light communications using 4 x 4 MIMO," in IEEE Photonics Technology Letters, vol. 26, no. 9, pp. 945-948, May1, 2014.

[35] S. Rajbhandari, A. V. N. Jalajakumari, H. Chun; G. Faulkner, K. Cameron, D. Tsonev, H. Haas, E. Xie, J. J. D. McKendry, J. J. D. Herrnsdorf, R. Ferreira, E. Gu, M. D. Dawson, D. C. O'Brien, "A multiGigabit/sec integrated multiple input multiple output VLC demonstrator," in Journal of Lightwave Technology , vol.PP, no.99, pp.1-1

[36] A. Mirvakili and V. J. Koomson, "High efficiency LED driver design for concurrent data transmission and PWM dimming control for indoor visible light communication," 2012 IEEE Photonics Society Summer Topical Meeting Series, Seattle, WA, 2012, pp. 132-133.

[37] S. Zhao, J. Xu and O. Trescases, "Burst-mode resonant LLC converter for an LED luminaire with integrated visible light communication for smart buildings," in IEEE Transactions on Power Electronics, vol. 29, no. 8, pp. 4392-4402, Aug. 2014.

[38] X. Deng, Y. Wu, K. Arulandu, G. Zhou and J. P. M. G. Linnartz, "Performance comparison for illumination and visible light communication system using buck converters," 2014 IEEE Globecom Workshops (GC Wkshps), Austin, TX, 2014, pp. 547-552.

[39] K. Modepalli and L. Parsa, "Dual-purpose offline LED driver for illumination and visible light communication," in IEEE Transactions on Industry Applications, vol. 51, no. 1, pp. 406-419, Jan.-Feb. 2015.

[40] S. Haese, L. Mtimet and M. Hélard, "LED driver performance analysis for joint visible light communication and illumination," 2016 IEEE 59th International Midwest Symposium on Circuits and Systems (MWSCAS), Abu Dhabi, 2016, pp. 1-4.

[41] J. G. Proakis, Digital communications, 4th ed. New York: McGrawHill, 2000 
[42] J. Vucic, C. Kottke, S. Nerreter, A. Buttner, K. D. Langer and J. W. Walewski, "White light wireless transmission at $200\{+\} \mathrm{Mb} / \mathrm{s}$ net data rate by use of discrete-multitone modulation," in IEEE Photonics Technology Letters, vol. 21, no. 20, pp. 1511-1513, Oct.15, 2009.

[43] J. Vucic, C. Kottke, S. Nerreter, K. D. Langer and J. W. Walewski, "513 Mbit/s visible light communications link based on DMT-modulation of a white LED," in Journal of Lightwave Technology, vol. 28, no. 24, pp. 3512-3518, Dec.15, 2010

[44] A. M. Khalid et al., "1-Gb/s transmission over a phosphorescent white LED by using rate-adaptive discrete multitone modulation," IEEE Photon. J., vol. 4, no. 5, Oct. 2012, pp. 1465-73

[45] C. Kottke, J. Hilt, K. Habel, J. Vučić and K. D. Langer, "1.25 Gbit/s visible light WDM link based on DMT modulation of a single RGB LED luminary," 2012 38th European Conference and Exhibition on Optical Communications, Amsterdam, 2012, pp. 1-3.

[46] H. Li, X. Chen, J. Guo, Z. Gao and H. Chen, "An analog modulator for $460 \mathrm{MB} / \mathrm{S}$ visible light data transmission based on OOK-NRS modulation," in IEEE Wireless Communications, vol. 22, no. 2, pp. 68 73, April 2015.

[47] G. Campo-Jimenez, R. Perez-Jimenez, F. Lopez-Hernandez, "Constraints on drivers for visible light communications emitters based on energy efficiency", Opt. Express, vol. 24, pp. 9994-9999, 2016.

[48] J. Sebastián, D.G. Aller, J. Rodriguez, D.G. Lamar and P.F. Miaja, "On the role of the power electronics on visible light communication," 2017 IEEE Applied Power Electronics Conference and Exposition (APEC), Tampa, 2017.

[49] J. Rodriguez, D.G. Lamar, J. Sebastian and P.F. Miaja, "Taking advantage of the output voltage ripple of a two-phase buck converter to perform quadrature amplitude modulation for visible light communication,” 2017 IEEE Applied Power Electronics Conference and Exposition (APEC), Tampa, 2017.

[50] C. H. Yeh, Y. F. Liu, C. W. Chow, Y. Liu, P. Y. Huang, H. K. Tsang, "Investigation of 4-ASK modulation with digital filtering to increase 20 times direct modulation speed of white-light LED visible light communication system", Opt. Express, vol. 20, no. 15, pp. 16218-16223, Jul. 2012

[51] Y. Wang, R. Li, Y. Wang and Z. Zhang, "3.25-Gbps visible light communication system based on single carrier frequency domain equalization utilizing an RGB LED," OFC 2014, San Francisco, CA, 2014, pp. 1-3.

[52] Y. Wang and N. Chi, "Demonstration of high-speed $2 \times 2$ non-imaging MIMO Nyquist single carrier visible light communication with frequency domain equalization," in Journal of Lightwave Technology, vol. 32, no. 11, pp. 2087-2093, June1, 2014.

[53] M. A. Kashani and M. Kavehrad, "On the performance of single- and multi-carrier modulation schemes for indoor visible light communication systems," 2014 IEEE Global Communications Conference, Austin, TX, 2014, pp. 2084-2089.

[54] S. Long, M. A. Khalighi, M. Wolf, Z. Ghassemlooy and S. Bourennane, "Performance of carrier-less amplitude and phase modulation with frequency domain equalization for indoor visible light communications," 2015 4th International Workshop on Optical Wireless Communications (IWOW), Istanbul, 2015, pp. 16-20.

[55] P. Deng, and M. Kavehrad, "Real-time software-defined single-carrier QAM MIMO visible light communication system," in 2016 Integrated Communications Navigation and Surveillance (ICNS)(2016), pp. 5A31-5A3-11.

[56] S. Pergoloni, A. Petroni, T. Bui, G. Scarano, R. Cusani, and M. Biagi, "ASK-based spatial multiplexing RGB scheme using symbol-dependent self-interference for detection," Opt. Express 25, 15028-15042 (2017)

[57] K. O. Akande and W. O. Popoola, "Synchronization of carrierless amplitude and phase modulation in visible light communication," 2017 IEEE International Conference on Communications Workshops (ICC Workshops), Paris, 2017, pp. 156-161.

[58] A. H. Abdolhamid and D. A. Johns, "A comparison of CAP/QAM architectures," Circuits and Systems, 1998. ISCAS '98. Proceedings of the 1998 IEEE International Symposium on, Monterey, CA, 1998, pp. $316,316 / 1-316 / 3$ vol.4

[59] B. Sklar, Digital communications. Vol. 2. Upper Saddle River: Prentice Hall, 2001.

[60] G. L. Stüber, Principles of mobile communication. Springer Science \&
Business Media, 2011.

[61] J. R. Barry, E. A. Lee, and D. G. Messerschmitt. Digital communication. Springer Science \& Business Media, 2012.

[62] E. McCune, Practical digital wireless signals. Cambridge University Press, 2010.

[63] D. G. Holmes and T. A. Lipo, Pulse width modulation for power converters. Piscataway, NJ: IEEE Press Series on Power Engineering, 2003, ch. 3, pp. 95-154.

[64] M. Hoyerby and M. Andersen, "Carrier distortion in hysteretic selfoscillating class-D audio power amplifiers: Analysis and Optimization," IEEE Trans. Power Electron., vol. 24, no. 3, pp. 714-729, Mar. 2009.

[65] F. H. Raab et al., "Power amplifiers and transmitters for RF and microwave," in IEEE Transactions on Microwave Theory and Techniques, vol. 50, no. 3, pp. 814-826, Mar 2002.

[66] V. Yousefzadeh, E. Alarcón and D. Maksimovic, "Three-level buck converter for envelope tracking applications," in IEEE Transactions on Power Electronics, vol. 21, no. 2, pp. 549-552, March 2006.

[67] M. C. W. Hoyerby and M. E. Andersen, "High-bandwidth, highefficiency envelope tracking power supply for 40W RF power amplifier using paralleled bandpass current sources," IEEE Power Electronics Specialists Conference, Recife, 2005, pp. 2804-2809.

[68] M. Rodríguez, P. F. Miaja, A. Rodríguez and J. Sebastián, "a multipleinput digitally controlled buck converter for envelope tracking applications in radiofrequency power amplifiers," in IEEE Transactions on Power Electronics, vol. 25, no. 2, pp. 369-381, Feb. 2010.

[69] Y. Zhang, M. Rodríguez and D. Maksimović, "100 MHz, 20 V, 90\% efficient synchronous buck converter with integrated gate driver," IEEE Energy Conversion Congress and Exposition (ECCE), Pittsburgh, PA, 2014, pp. 3664-3671.

[70] J. Sebastián, P. Fernández-Miaja, F. J. Ortega-González, M. Patiño and M. Rodríguez, "Design of a two-phase buck converter with fourth-order output filter for envelope amplifiers of limited bandwidth," in IEEE Transactions on Power Electronics, vol. 29, no. 11, pp. 5933-5948, Nov. 2014.

[71] J. Rodriguez, D. G. Aller, D. G. Lamar and J. Sebastian, "Energy efficient visible light communication transmitter based on the split of the power," 2017 IEEE Energy Conversion Congress and Exposition (ECCE), Cincinnati, OH, USA, 2017, pp. 217-224.

[72] J. Sebastián, P. Fernández-Miaja, A. Rodríguez and M. Rodríguez, "Analysis and design of the output filter for buck envelope amplifiers," in IEEE Transactions on Power Electronics, vol. 29, no. 1, pp. 213-233, Jan. 2014.

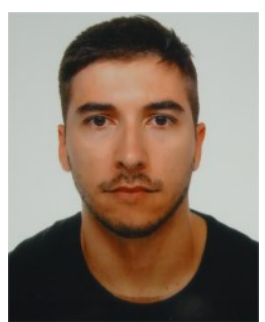

Juan Rodríguez (S'15) was born in Avilés, Spain, in 1991. He received the M.Sc. degree in telecommunication engineering from the University of Oviedo, Spain, in 2014, where he is currently working towards the Ph.D. degree in electrical engineering.

His research interests are focused on high-frequency DC-DC power converters, wide bandgap semiconductors and LED drivers for visible light communication.

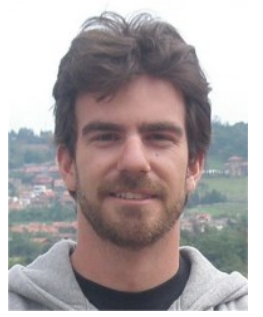

Pablo F. Miaja (S'07, M'13) was born in Oviedo, Spain, in 1984. He received the M.S. degree in telecommunication engineering from the University of Oviedo (Spain) in 2007 and in 2012 the $\mathrm{PhD}$. degree from the same university. Between December 2007 and November 2014 he worked as a researcher at the Electronic 
Power Supply Systems Group of the University of Oviedo. Between November 2014 and May 2016 he was a Research Associate at the Power conversion Group of the University of Manchester (U.K). Since June 2016 he is a contractor for the Power Management \& Distribution Section of the European Space Agency, based in The Netherlands.

His research interests include DC/DC conversion, digital control of switched converters, $\mathrm{GaN}$ and $\mathrm{SiC}$ semiconductor devices, and power management systems.

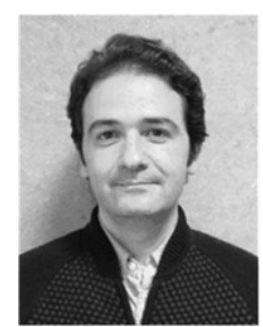

Diego G. Lamar (M'08) was born in Zaragoza, Spain, in 1974. He received the M.Sc. degree, and the Ph.D. degree in Electrical Engineering from the University of Oviedo, Spain, in 2003 and 2008, respectively.

In 2003 and 2005 he became a Research Engineer and an Assistant Professor, respectively at the University of Oviedo.

Since September 2011, he has been an Associate Professor.

His research interests are focused in switching-mode power supplies, converter modelling, and power-factor-correction converters.

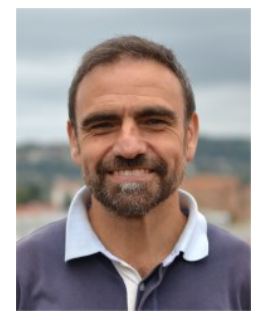

Javier Sebastián (M'87, SM'11) was born in Madrid, Spain, in 1958. He received the M.Sc. degree from the Technical University of Madrid (UPM), and the Ph.D. degree from the University of Oviedo, Spain, in 1981 and 1985, respectively. He was an Assistant Professor and an Associate Professor at both the UPM and the University of Oviedo. Since 1992, he has been with the University of Oviedo, where he is currently a Professor.

His research interests are switching-mode power supplies, modeling of dc-to-dc converters, low output voltage dc-to-dc converters, high power factor rectifiers, LED drivers, dc-to-dc converters for envelope tracking techniques and the use of wide band-gap semiconductors in power supplies. 